\title{
Vertical Motions in Arctic Mixed-Phase Stratiform Clouds
}

\author{
Matthew D. Shupe \\ Cooperative Institute for Research in Environmental Science, and NOAA/Earth System Research Laboratory, Boulder, Colorado \\ Pavlos Kollias \\ McGill University, Montreal, Quebec, Canada \\ P. Ola G. Persson \\ Cooperative Institute for Research in Environmental Science, and NOAA/Earth System Research Laboratory, Boulder, Colorado
}

GREG M. MCFARQUHAR

University of Illinois at Urbana-Champaign, Urbana, Illinois

(Manuscript received 26 March 2006, in final form 6 August 2007)

\begin{abstract}
The characteristics of Arctic mixed-phase stratiform clouds and their relation to vertical air motions are examined using ground-based observations during the Mixed-Phase Arctic Cloud Experiment (MPACE) in Barrow, Alaska, during fall 2004. The cloud macrophysical, microphysical, and dynamical properties are derived from a suite of active and passive remote sensors. Low-level, single-layer, mixed-phase stratiform clouds are typically topped by a 400-700-m-deep liquid water layer from which ice crystals precipitate. These clouds are strongly dominated ( $85 \%$ by mass) by liquid water. On average, an in-cloud updraft of 0.4 $\mathrm{m} \mathrm{s}^{-1}$ sustains the clouds, although cloud-scale circulations lead to a variability of up to $\pm 2 \mathrm{~m} \mathrm{~s}^{-1}$ from the average. Dominant scales-of-variability in both vertical air motions and cloud microphysical properties retrieved by this analysis occur at $0.5-10-\mathrm{km}$ wavelengths. In updrafts, both cloud liquid and ice mass grow, although the net liquid mass growth is usually largest. Between updrafts, nearly all ice falls out and/or sublimates while the cloud liquid diminishes but does not completely evaporate. The persistence of liquid water throughout these cloud cycles suggests that ice-forming nuclei, and thus ice crystal, concentrations must be limited and that water vapor is plentiful. These details are brought together within the context of a conceptual model relating cloud-scale dynamics and microphysics.
\end{abstract}

\section{Introduction}

Vertical motions leading to condensation are a fundamental mechanism for the formation of both liquid and ice in many types of clouds (e.g., Heymsfield 1975; Hogan et al. 2002; Lothon et al. 2005). In mixed-phase clouds, in particular, moderate to strong vertical motions are needed to support liquid water condensation in the presence of cloud ice at supercooled temperatures (Rauber and Tokay 1991). In this three-phase situation, cloud ice can grow at the expense of liquid water due to the lower saturation vapor pressure of ice

Corresponding author address: Matthew Shupe, R/PSD3, 325 Broadway, Boulder, CO 80305.

E-mail: matthew.shupe@noaa.gov (the Bergeron-Findeisen mechanism) and thus will fully glaciate the cloud if the total condensate supply rate does not exceed the rate of ice diffusional growth. However, in addition to vertical motions, other conditions support the growth of liquid water, making the exact mechanisms and feedbacks in operation in these clouds unclear.

In the Arctic, extensive stratiform mixed-phase cloud layers are observed (Herman and Goody 1976) and may persist in a quasi steady state for time periods of up to days and even weeks (Shupe et al. 2006). Although it is clear that cloud-top radiative cooling is largely responsible for driving vertical air motions that form the liquid in these clouds (Curry 1986; Pinto 1998), it is still uncertain what role other mechanisms play and how multiple phases can exist in a colloidally unstable state 
for such extended periods of time. Some model studies, such as the cloud-resolving simulations of Harrington et al. (1999) and Jiang et al. (2000), demonstrate that mixed-phase clouds persist only under limited concentrations of ice-forming nuclei (IFN). Furthermore, there is some indication that the type of IFN and ice initiation mechanism may have an important role in defining the cloud phase balance and persistence (Morrison et al. 2005b). In addition, Herman and Goody (1976) suggest that the stationarity of the synoptic flow in the central Arctic acts to minimize mechanisms of stratus dissipation. Curry (1986) asserts that surface fluxes are not responsible for Arctic stratus formation under the strongly stable conditions present in winter and early spring, but this may not be the case for late spring through October when open ocean is a significant factor (Pinto and Curry 1995; Olsson and Harrington 2000). Although many details of these cloud formation and persistence processes are not well understood, cloud-scale vertical motions are a key feature of mixed-phase clouds that affect their evolution and support their extended lifetimes (e.g., Rauber and Tokay 1991).

The partitioning of phases in mixed-phase clouds may play an important climatic role in the Arctic, where the surface radiation balance is critical due to the sea ice and snow-covered surface. Cloud liquid and ice have substantially different impacts on atmospheric radiation due to differences in particle size, shape, density, concentration, and refractive index (Sun and Shine 1994). As a result of these differences, it is the cloud liquid that has a dominant influence over the radiative effects of clouds on the Arctic surface (Hogan et al. 2003a; Shupe and Intrieri 2004; McFarquhar and Cober 2004; Zuidema et al. 2005). Past observations have shown a clustering of cloud phases on various scales, which can have a large impact on the cloud radiative effect (McFarquhar and Cober 2004). In addition, the balance of phases affects the precipitation efficiency and flux (Harrington and Olsson 2001; Zhang and Lohmann 2003) and thereby the Arctic hydrologic cycle. These climatic factors emphasize the importance of understanding the cloud-scale processes that determine the partitioning of cloud phases.

Large-scale models are unable to resolve the localscale cloud processes and motions that lead to the local formation of cloud liquid, and therefore cloud formation is often highly parameterized. Even mesoscale models are unable to sufficiently resolve motions that occur at scales of less than a few kilometers. A particularly pressing issue in cloud and climate modeling is the ability to appropriately partition cloud water between phases (Gregory and Morris 1996). Models typically prescribe the fraction of cloud condensate that is liquid according to a temperature relationship that varies widely among models. Many of these models limit liquid water to relatively warm temperatures [e.g., $-23^{\circ} \mathrm{C}$ (Tiedtke 1993), $-15^{\circ} \mathrm{C}$ (Smith 1990; Boucher et al. 1995), $-9^{\circ} \mathrm{C}$ (Gregory and Morris 1996)], and since cloud liquid is actually observed at temperatures below $-30^{\circ} \mathrm{C}$ (Heymsfield et al. 1991; Intrieri et al. 2002; Korolev et al. 2003), many models underpredict liquid at cold temperatures in the Arctic (e.g., Hogan et al. 2003b). Shupe et al. (2006) suggest that the partitioning of phase is not simply a function of temperature, but must incorporate other key factors that contribute to the observed $20^{\circ} \mathrm{C}$ range of temperature for any given ratio of cloud phases. Tremblay et al. (1996) propose that the liquid partitioning should be accomplished using multiple parameters, including large-scale vertical motions, although Hogan et al. (2003a) point out that it is more likely the subgrid-scale convection and waves that are important in liquid formation. Furthermore, the IFN may need to be considered in a parameterization of the phase partitioning (e.g., Pinto 1998; Harrington et al. 1999; Morrison et al. 2005a). More observational support is needed to elucidate and characterize the important processes that are responsible for partitioning cloud phase, as well as the horizontal and vertical scales over which the different cloud phases occur and mix.

The intent of this paper is to examine the role of vertical air motions in Arctic mixed-phase clouds and in particular their impact on, and relation to, other cloud properties including the microphysics, macrophysics, and persistence. All cloud properties, including the vertical motions, are derived from ground-based remote sensors that were operated at the Department of Energy's Atmospheric Radiation Measurement (ARM) Climate Research Facility (ACRF) on the North Slope of Alaska (NSA), located near the coastal town of Barrow, Alaska $\left(71.323^{\circ} \mathrm{N}, 156.616^{\circ} \mathrm{W}\right)$. Observations coincide with the Mixed-Phase Arctic Cloud Experiment (MPACE; Verlinde et al. 2007), which took place in fall 2004.

\section{Instruments}

The vertically pointing, 35-GHz Millimeter Cloud Radar (MMCR; Moran et al. 1998) has been frequently employed in cloud studies. Here, only the "stratus" mode is utilized, which has been optimized for observing low-level clouds (Kollias et al. 2007) and has a minimum detectable reflectivity of $-50 \mathrm{dBZ}$ at $1 \mathrm{~km}$. The MMCR records vertically resolved measurements of the Doppler spectrum, which is the distribution of re- 
turned radar power as a function of hydrometeor radial velocity in the radar volume. In addition, the first three moments of the Doppler spectrum - the reflectivity, mean Doppler velocity, and Doppler spectrum variance (and its square root, the "spectrum width")-are utilized here. For velocity measurements, the convention is that positive velocities are toward the radar, or down.

A high spectral resolution lidar (HSRL; Eloranta 2005) was deployed at the NSA site during the MPACE time period. This $532-\mathrm{nm}$ system provides profiles of calibrated backscatter and depolarization ratio, which are both crucial for determining cloud phase, through aerosols and clouds up to an optical depth of $\sim 4$, above which the lidar beam is attenuated.

Measurements of temperature, relative humidity, and wind speed were made by periodic radiosonde ascents with a temporal frequency that varied from 4 day $^{-1}$ during intensive observation periods to 1 day $^{-1}$ during standard operations at MPACE. Radiosondes were launched from two sites-one collocated with the other sensors and one at a distance of $\sim 2 \mathrm{~km}$ from the instrument site. Radiosonde relative humidity measurements often suffer from a dry bias, particularly at high altitudes, and have a manufacturer-estimated uncertainty of $5 \%$. While the uncertainty of low-altitude moisture measurements utilized in this study is likely smaller than $5 \%$, these uncertainties must still be considered when interpreting the moisture data. For use in the retrieval calculations, measured profiles are interpolated in time to cover the time periods of interest. For specific analysis of cloud properties that pertain to sounding quantities, the interpolated sounding data are only utilized within \pm 15 min from the radiosonde launch.

Brightness temperature measurements at 23.8 and $31.4 \mathrm{GHz}$ from a microwave radiometer (MWR) provide estimates of the total condensed liquid water path $\left[\operatorname{LWP}\left(\mathrm{g} \mathrm{m}^{-2}\right)\right]$ and the precipitable water vapor based on variable coefficient, bilinear, statistical retrievals (Liljegren et al. 2001; Turner et al. 2007). The expected uncertainty in the retrieved LWP due to retrieval and instrument errors in the Arctic environment is $\sim 25 \mathrm{~g}$ $\mathrm{m}^{-2}$ (Westwater et al. 2001).

\section{Methods}

\section{a. Identifying cloud phase}

Cloud phase identification is a prerequisite to performing cloud retrievals to ensure that the proper methods are applied. In particular, retrievals of vertical velocity are only performed in cloud volumes that contain liquid water droplets, which are assumed to move with air motions (Shupe et al. 2008). Similarly, liquid and ice microphysical retrievals are only applied in regions where these phases exist. A full description of the cloud phase classifier is given by Shupe (2007), while a brief summary of salient points is provided here. Measurements during a case study from 1400 to 1700 UTC 28 October at MPACE (Fig. 1) stand as an example for the general classification.

Lidar measurements provide information on cloud particle shape and cross-sectional area, which are important for phase identification. Cloud liquid is identified by high lidar backscatter and low depolarization ratio (e.g., Sassen 1984; Intrieri et al. 2002; Shupe 2007), which indicate numerous, spherical particles. Liquid is indicated near the top of the lidar returns in Figs. 1d,e. On the contrary, nonspherical ice crystals highly depolarize the lidar signal and are identified below $500 \mathrm{~m}$ in Figs. 1d,e. Since the lidar beam is attenuated by optically thick (often liquid) cloud layers, only single-layer clouds are considered here. Microwave radiometer retrievals of a positive LWP (see below) also support the presence of liquid water in this case. Radiosonde profiles show saturation with respect to water from the base of the liquid cloud identified by the lidar up to the top of the cloud identified by the radar, also indicating liquid water in this layer. Radar reflectivities, which nominally respond to the particle size to the sixth power, are dominated by cloud ice signals since ice crystals are typically much larger than liquid droplets. Reflectivity measurements (Fig. 1a) are higher than -17 $\mathrm{dB} Z$, which is the typical upper limit for cloud liquid droplets (Frisch et al. 1995), from the surface to near the top of the cloud returns observed by the radar, suggesting that cloud ice is present to near the cloud top.

This combination of measurements illustrates the basic structure of low-level, stratiform Arctic mixed-phase clouds (Fig. 2a). The cloud region above the lidar cloud base is mostly mixed phase, containing a layer of liquid water from which ice particles form and fall. Below the lidar cloud base (i.e., the cloud liquid base), only ice and snow exist down to the surface. This basic structure is also supported by 53 vertical profiles of in situ observations through single-layer boundary layer stratus made by the University of North Dakota Citation aircraft during MPACE (McFarquhar et al. 2007).

\section{b. Cloud property retrievals}

Vertical air motions are retrieved from radar Doppler spectra for all radar returns identified to contain liquid water, or in other words, those areas identified to be liquid or mixed phase. The method relies on an accurate identification of liquid cloud droplets and the assumption that these droplets trace the vertical air mo- 


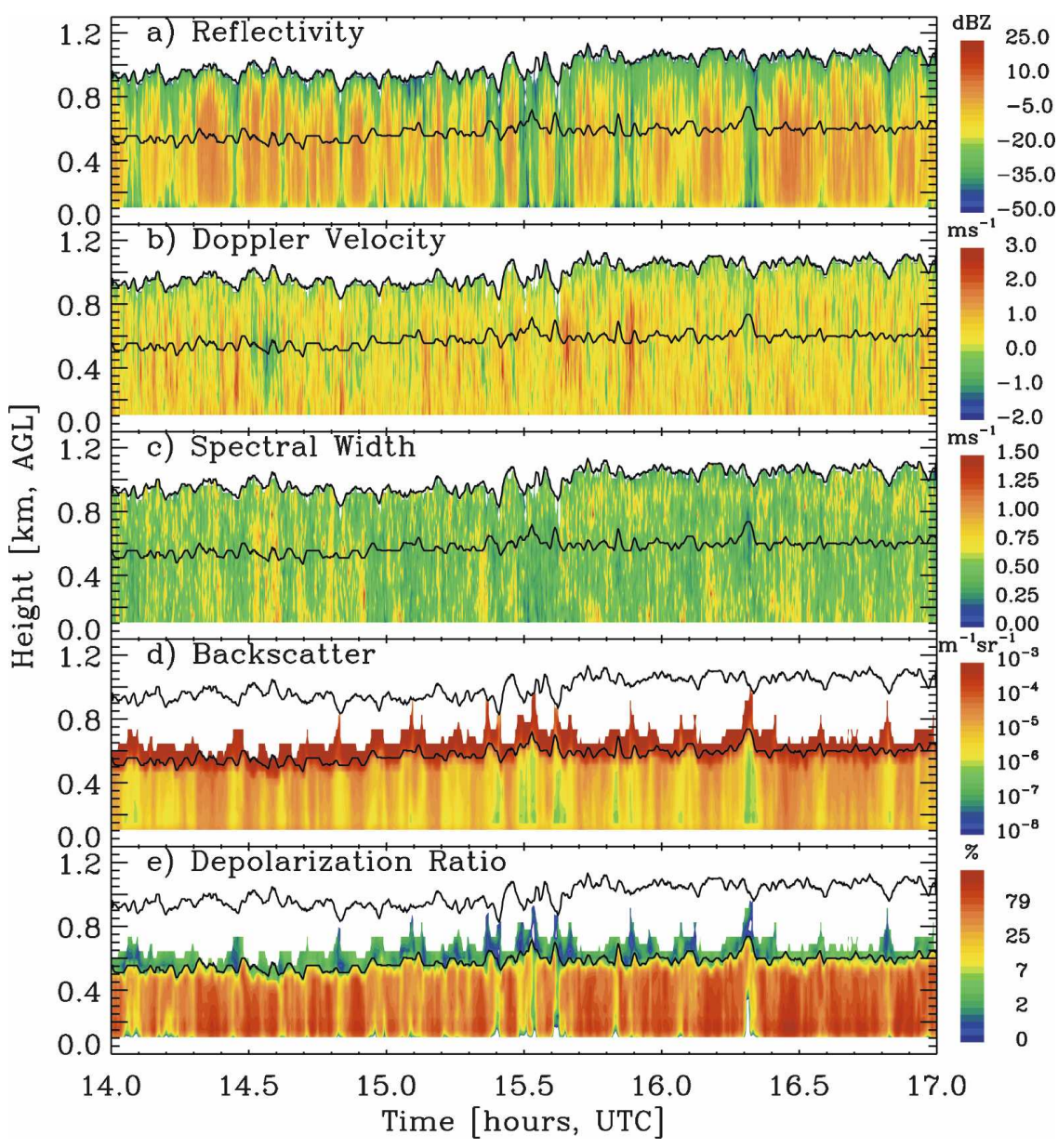

FIG. 1. Measurements on 28 Oct 2004 of radar (a) reflectivity, (b) mean Doppler velocity, (c) Doppler spectrum width, and lidar (d) backscatter and (e) depolarization ratio. In each panel, the base and top of the cloud liquid layer, identified from lidar and radar measurements, respectively, are plotted. A time resolution of $\sim 12 \mathrm{~s}$ is used for plotting, although the original data are at a higher temporal resolution.

tions (e.g., Kollias et al. 2001; Shupe et al. 2004). Based on this assumption, the low-velocity edge of the radar Doppler spectrum from a radar return containing liquid water corresponds to the signal from the liquid water, and therefore characterizes the vertical air motions. Minor corrections must be applied to account for spectral broadening terms that act to bias the low-velocity edge of the spectrum from its true value, which is attributable to the droplets alone. The details of this method, including the spectral broadening corrections and a resulting estimate of the turbulent dissipation rate from the temporal variance of mean Doppler velocity, are outlined by Shupe et al. (2008). That study suggests that the maximum uncertainty in retrieved vertical velocities is on the order of $0.2 \mathrm{~m} \mathrm{~s}^{-1}$.

Empirically derived equivalent radar reflectivity $\left(Z_{e}\right)$ retrievals are used to obtain both the ice water content
(IWC) and ice particle effective radius $\left[R_{\mathrm{ei}}\right.$, the $\mathrm{Fu}$ (1996) generalized effective radius] based on assumptions of a fixed particle density-size relationship, a relationship between size, mass, and radar reflectivity, and an exponential particle size distribution (Matrosov et al. 2002). Moreover, the reflectivity contribution from the ice component in mixed-phase conditions is assumed to strongly dominate over that from the liquid component. The linear coefficients for these retrievals were derived specifically for the fall months at the NSA site according to the method described by Shupe et al. (2005), resulting in the self-consistent relationships IWC $=0.04 \times Z_{e}^{0.63}$ and $R_{\mathrm{ei}}=54 Z_{e}^{0.059}$. The IWC relationship is consistent with the temperaturedependent reflectivity retrieval of Hogan et al. (2006) for the typical observed cloud temperature of $\sim-13^{\circ} \mathrm{C}$ in the clouds considered here. Shupe et al. (2006) sug- 


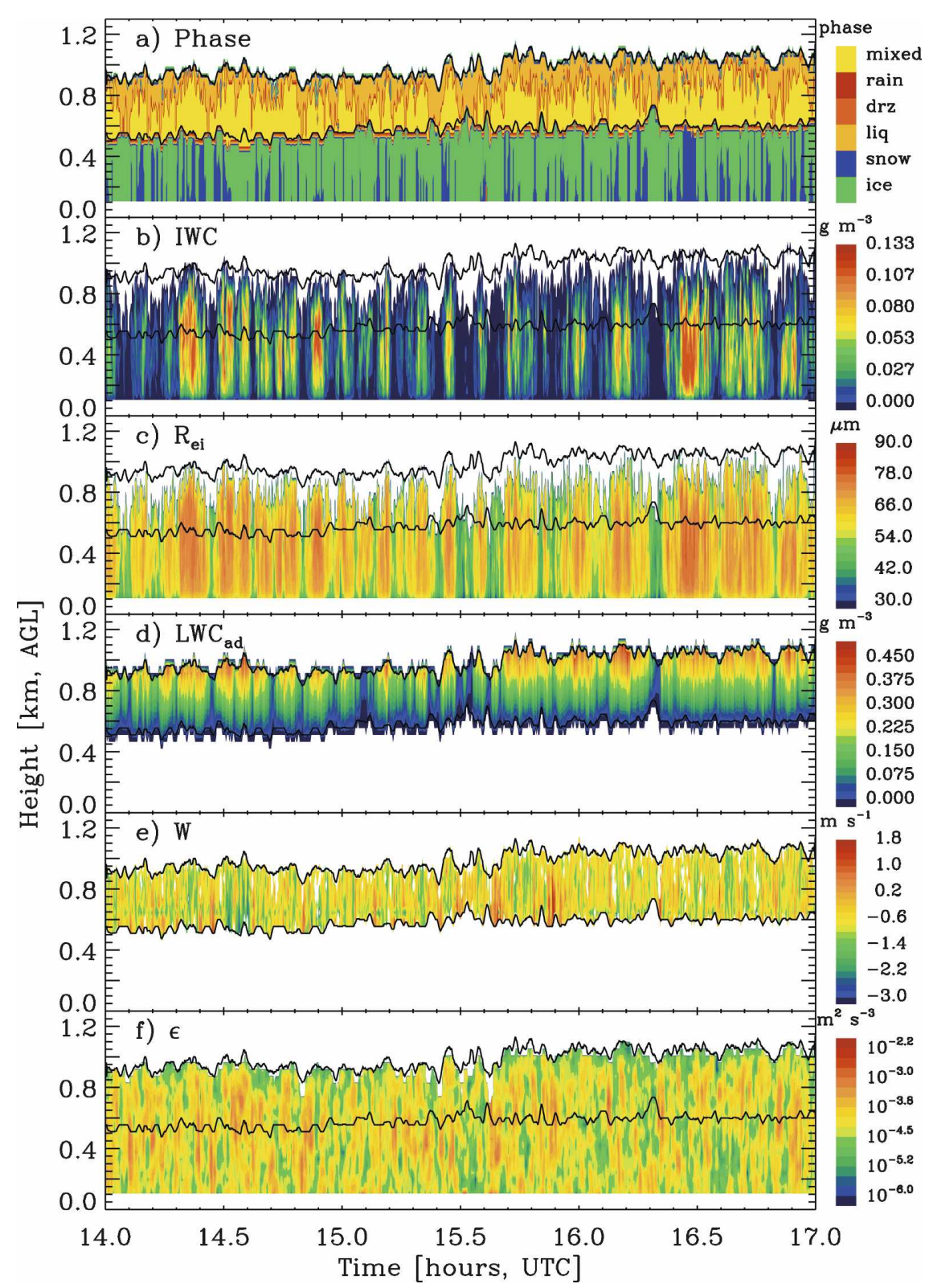

FIG. 2. Retrievals for the 28 Oct case of (a) cloud phase type, (b) ice water content, (c) ice particle effective radius, (d) adiabatic liquid water content, (e) vertical velocity, and (f) turbulent dissipation rate. In each panel, the base and top of the cloud liquid layer are plotted. A time resolution of $\sim 12 \mathrm{~s}$ is used for plotting, although the original data are at a higher temporal resolution.

gest that the uncertainty of this type of retrieval is $50 \%-75 \%$ for IWC and $\sim 40 \%$ for particle size.

Vertically resolved cloud liquid microphysical properties are not readily available from this suite of measurements. Thus, the cloud liquid is estimated by an adiabatic liquid water profile-computed from the lidar cloud base, radar cloud top, and radiosonde thermodynamic measurements- that is then scaled by the statistically derived MWR LWP. Aircraft observations indi- cate that the cloud liquid is not always adiabatically distributed in these clouds. Thus, the LWP-scaled adiabatic profiles utilized here likely estimate the correct amount of total liquid water, but may not always distribute that water correctly in the vertical.

\section{c. Power spectrum processing}

Power spectra are computed from time series of layer-averaged vertical motion and cloud property re- 
trievals in order to understand the scales-of-variability in action in these clouds. Time series segments of approximately $2.4 \mathrm{~h}$ are mean-centered and linearly detrended. A Hanning window is applied to each time segment to taper the data and minimize edge effects. The time resolution $(\sim 4 \mathrm{~s})$ and length of time record $(\sim 2.4 \mathrm{~h})$ used to compute the power spectra provide a good window for capturing cloud-scale to mesoscale motions. Synoptic-scale motions are not captured due to the low-frequency limit determined by the record length. Similarly, turbulent motions at frequencies higher than $\sim 0.1 \mathrm{~s}^{-1}$ are not captured due to the temporal resolution. Frequency is converted to wavelength using the radiosonde-measured horizontal wind speed. These wavelengths represent the variability of cloud features as they advect with the wind over the stationary NSA site and may not represent true spatial wavelengths of cloud features.

\section{Results}

Radar-based retrievals were applied to the subset of clouds observed at the NSA site from 27 September to 8 November 2004 that were single layer, persisted for at least $2 \mathrm{~h}$, and had a cloud top typically below $3 \mathrm{~km}$ in altitude. Thus, the results described here are most descriptive of the frequently occurring, low-level stratiform mixed-phase clouds. A total of $\sim 400 \mathrm{~h}$ of observations were utilized, which is approximately $40 \%$ of the possible time. Including multilayered scenes (which were not utilized in this study), mixed-phase clouds were present more than $70 \%$ of the time above the NSA site during MPACE. In all, the dataset is composed of only 9 different continuous cloud systems. Three of these systems lasted for 3-4 h, three lasted for 12-24 h, one lasted for $60 \mathrm{~h}$, one was a continuous single-layered cloud for $134 \mathrm{~h}$ ( $>5$ days), and one consisted of $137 \mathrm{~h}$ of single-layer mixed-phase cloud embedded in a time period of $251 \mathrm{~h}$ (nearly 11 days) of continuous mixed-phase cloudiness (which included multilayer clouds).

\section{a. An example case study}

The case study from 1400 to 1700 UTC 28 October demonstrates retrieval results and the fundamental macrophysical, microphysical, and dynamical structure of autumn Arctic low-level, stratiform mixed-phase clouds (Figs. 2-4). During this case, the layer of cloud liquid near cloud top remains 300-500 m thick, but the base lifts from about 500 to $600 \mathrm{~m}$. The LWP oscillates between nearly zero and $140 \mathrm{~g} \mathrm{~m}^{-2}$ as the cloud system advects over the NSA site, but typically does not dis- appear altogether. IWC and $R_{\mathrm{ei}}$ increase from near cloud top to just below the base of the cloud liquid and, along with the IWP, exhibit periodic bursts of ice production. At a few points, the IWP is nearly equal to the LWP, but the liquid fraction $[\mathrm{LF}=\mathrm{LWP} /(\mathrm{LWP}+$ IWP)] is most often greater than 0.7 , revealing the predominance of liquid condensate. Vertical motions (which are only derived where liquid water is present) are relatively vertically coherent, with a mean upward motion and periodic up- and downdrafts relative to the mean state. Turbulent dissipation rates are highly variable with no clear vertical trends, and vary from about $10^{-5}$ to $10^{-3} \mathrm{~m}^{2} \mathrm{~s}^{-3}$. Power spectra of vertical motions, LWP, and the cloud ice properties at this time show similarities in their scales-of-variability (Fig. 4). All have a broad peak in power, which for the microphysical properties is the dominant peak, at wavelengths of 5-10 km. In particular for the vertical motions, but also for the microphysics, there are important scales-ofvariability at $0.5-$ to $4-\mathrm{km}$ wavelengths. For the vertical motions, the nearly $-2 / 3$ slope at the high-frequency end of the spectrum suggests that in this case the turbulent inertial subrange may have been captured (e.g., Curry et al. 1988; Gultepe and Starr 1995).

A magnified subset of the case (Fig. 5) reveals a periodic behavior that includes the response of various cloud properties to the vertical motions. As the strength of an updraft increases, the cloud top lifts, the LWP and IWP increase, and the ice particles grow. In neutral or downward motions, the cloud top descends, the IWP is usually fully depleted, and the LWP decreases but the liquid does not fully evaporate. These features therefore lead to a decreasing ratio of total liquid to total ice in an updraft. Only at two points during the full case does the total ice mass surpass the liquid mass; once when the liquid is nearly absent, and the second during a major ice pulse at 1630 UTC revealed by very large IWCs (Fig. 2a). The case detail (Fig. 5) shows vertical velocity fluctuations at scales of 1,3 , and $7 \mathrm{~km}$, while the cloud microphysics predominantly respond to the $7-\mathrm{km}$ motions. There is a suggestion that the liquid water initially increases most quickly in response to an updraft, while the response of the ice component is slightly slower than that of the liquid component.

\section{b. Autumn results from Barrow}

The single-layer mixed-phase cloud properties from autumn 2004 at Barrow are summarized in Figs. 6-9 and Table 1. Specifically, cloud-layer height and thickness results are given in Fig. 6. For this subset of stratiform clouds, the cloud top is typically near $1 \mathrm{~km}$, but varies from 0.5 to $2 \mathrm{~km}$. The base of the cloud ice al- 


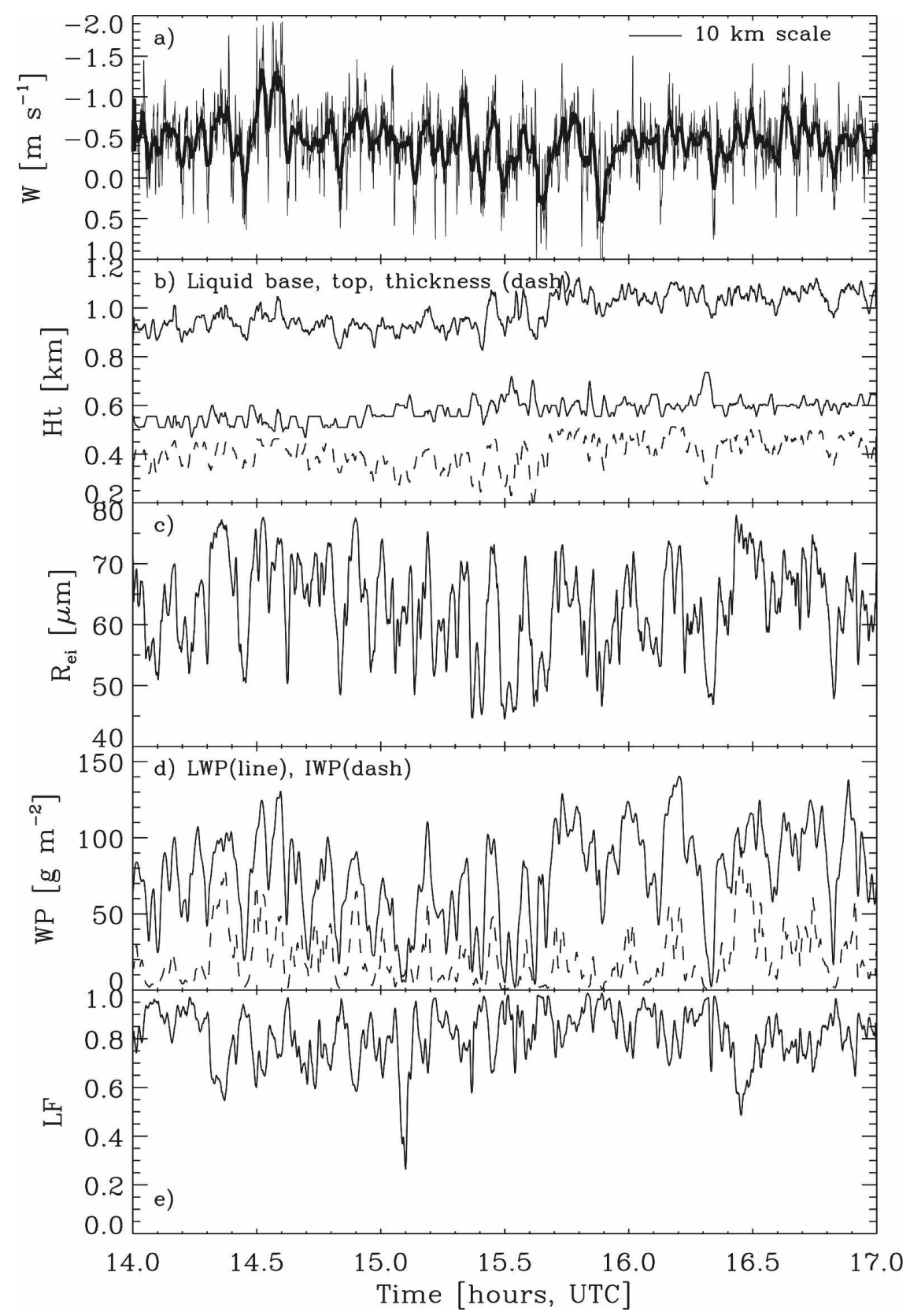

FIG. 3. Retrievals for the 28 Oct case of (a) layer-averaged vertical velocity, (b) cloud liquid base and top heights (lines) and total thickness (dash), (c) layer-averaged ice particle effective radius, (d) liquid (line) and ice (dash) water paths, and (e) the liquid fraction defined as LWP/(LWP + IWP). A 9-point ( $\sim 40$ s) smoothing window has been applied for clarity, except in (a) where the data are plotted in both native resolution $(\sim 4 \mathrm{~s})$ and with a 19-point $(\sim 80 \mathrm{~s})$ smoothing window (thick line). The bar plotted in (a) is equivalent to a length scale of $10 \mathrm{~km}$, based on a typical horizontal wind speed for this time period of $13 \mathrm{~m} \mathrm{~s}^{-1}$.

most always extends to the surface (or the lowest radar range gate), while the base of the cloud liquid resides above that of the cloud ice and is most often at $0.6-0.7$ $\mathrm{km}$. Cloud liquid layers are $0.3-0.8 \mathrm{~km}$ deep, while the liquid plus ice thickness is typically twice that depth.
Results related to radiosonde measurements are provided in Fig. 7 and are based on time periods within 15 min of the radiosonde launch under the assumption that the conditions measured by the radiosondes will not change appreciably over that short time period. The 

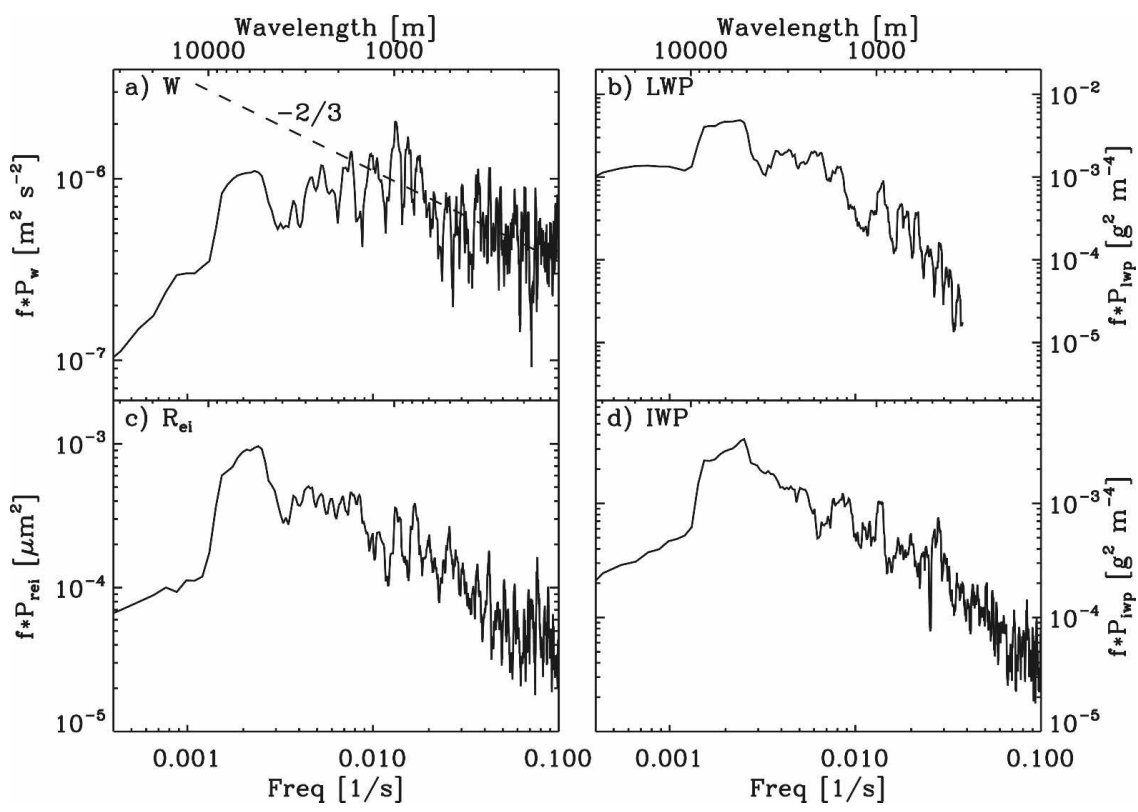

FIG. 4. Power spectra for the 28 Oct case of (a) layer-averaged vertical velocity, (b) LWP, (c) ice particle $R_{\mathrm{ei}}$, and (d) IWP. The wavelength axis on the top has been estimated based on a typical horizontal wind speed for this time period of $13 \mathrm{~m} \mathrm{~s}^{-1}$.

distribution of cloud-top temperatures, which largely determine the initial ice crystal growth regime, ranges from $-18^{\circ}$ to $-4^{\circ} \mathrm{C}$. The cloud top is most often near, or slightly above, the base of the temperature inversion, but can vary by a few hundred meters in either direction due to cloud-scale variability. The temperature lapse rate across the cloud liquid layer is most often about $-7^{\circ} \mathrm{C} \mathrm{km}^{-1}$ but can be as large as $-10^{\circ} \mathrm{C} \mathrm{km}^{-1}$ or even slightly positive. For examining the association of moisture profiles with the cloud layers, "saturated" conditions are considered those with a relative humidity greater than $98 \%$ (which takes into account a possible dry bias in the radiosondes). Even including this lenient definition of saturation, the observed cloud liquid base and top both usually extend outside the saturated layer (Fig. 7d). Typically the liquid cloud layer occurs over the layer where relative humidities are larger than $95 \%$. Saturations slightly below $100 \%$ are consistent with the analysis of Korolev and Isaac (2006), which suggests that dry pockets associated with small-scale holes in the cloud layer might lower the average saturation. Their analysis from aircraft measurements showed typical saturations of $97 \%-100 \%$ in mixed-phase clouds. The layer of saturation with respect to ice extends both above and below the layer of saturation with respect to water by up to $350 \mathrm{~m}$ (Fig. $7 \mathrm{e})$. Finally, the level of maximum IWC in the vertical column most often occurs within $300 \mathrm{~m}$ of the base of the ice saturated layer and the base of the cloud liquid
(Fig. 7f), which both happen to be at nearly the same height on average.

Liquid water paths range from near zero to $400 \mathrm{~g}$ $\mathrm{m}^{-2}$, with a median value of $\sim 150 \mathrm{~g} \mathrm{~m}^{-2}$ (Fig. 8a). The distribution of adiabatically computed LWP is more weighted by larger paths, while there are a few cases when the retrieved LWP is actually larger than the estimated adiabatic LWP (Fig. 8b), indicating superadiabatic conditions, an overestimate of the retrieved LWP, or an underestimate of the adiabatic value. Ice water paths range up to about $200 \mathrm{~g} \mathrm{~m}^{-2}$ but, because of the frequent occurrence of low amounts of cloud ice, the median is only $15 \mathrm{~g} \mathrm{~m}^{-2}$ (Fig. 8d). The liquid fraction shows a distribution where nearly $95 \%$ of the data are larger than 0.5 (Fig. 8c), and the liquid phase composes $85 \%$ of the total condensed mass, on average. This phase fractionation is similar to the analysis of in situ aircraft observations at MPACE, which showed liquid water fractions ranging from averages of $96 \%$ near cloud top to $70 \%$ near the base of the cloud liquid (McFarquhar et al. 2007). Vertically, the IWC is usually at a maximum somewhere near the middle of the total (liquid + ice) cloud system (Fig. 8e), which roughly corresponds to the base of the cloud liquid and the base of the layer that is supersaturated with respect to ice (i.e., Fig. 7f). The median retrieved IWC and $R_{\mathrm{ei}}$ are $0.006 \mathrm{~g} \mathrm{~m}^{-3}$ and $46 \mu \mathrm{m}$, respectively, both of which are smaller than those retrieved via a similar analysis in mixed-phase clouds over the Arctic Ocean in 1998, par- 


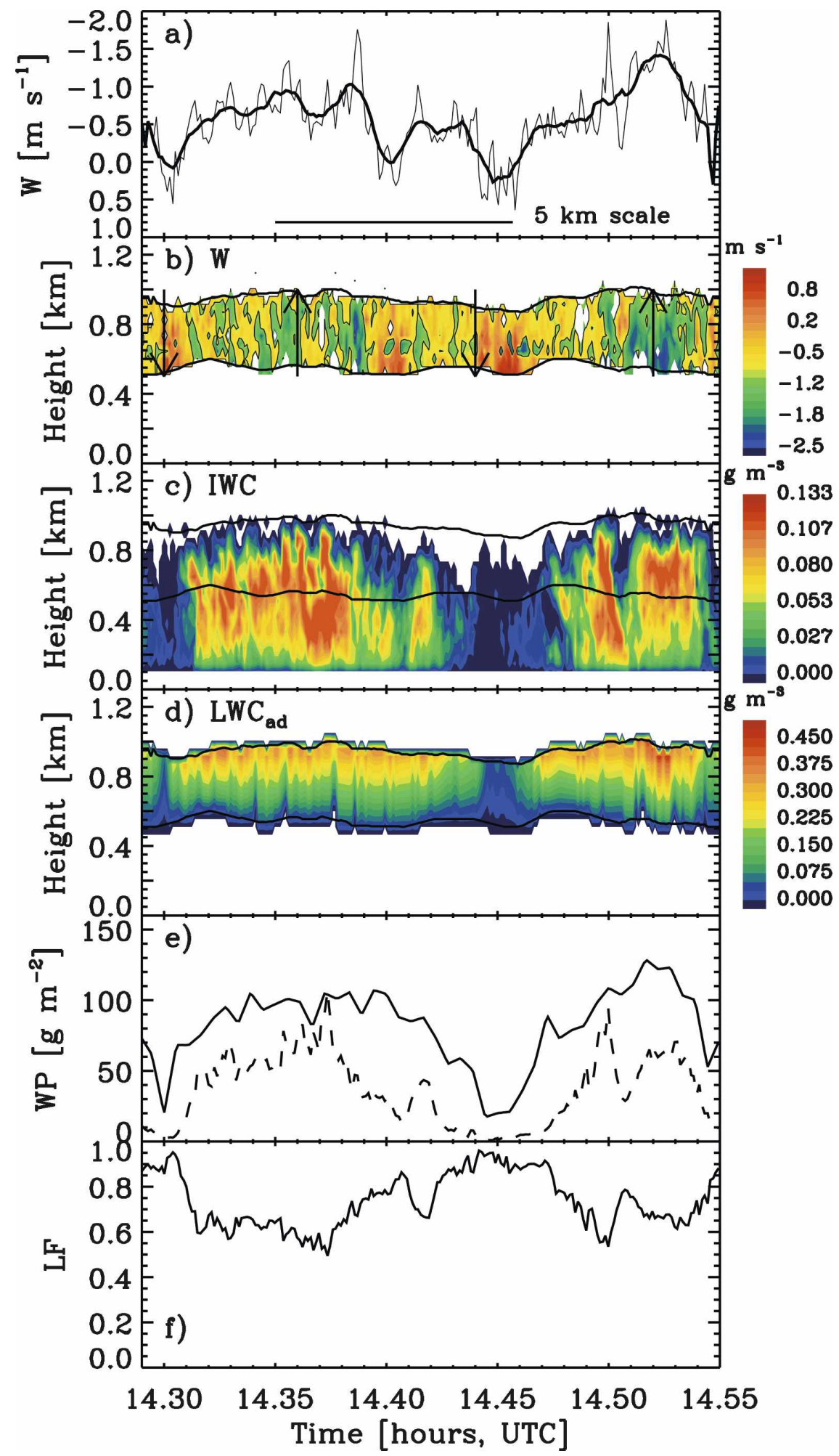

FIG. 5. Circulations during 28 Oct case, including (a) layer-averaged vertical velocity, (b) vertically resolved vertical velocity, (c) IWC, (d) LWC, (e) liquid (solid) and ice (dashed) water paths, and (f) the liquid fraction, or LWP/(LWP + IWP). Liquid cloud boundaries are included in (b), (c), and (d). In (a), both the full resolution and a 45-s running average are plotted as well as a bar representing a 5-km length scale. In (b), a black contour line delineates the contour of average vertical velocity for this time period. 

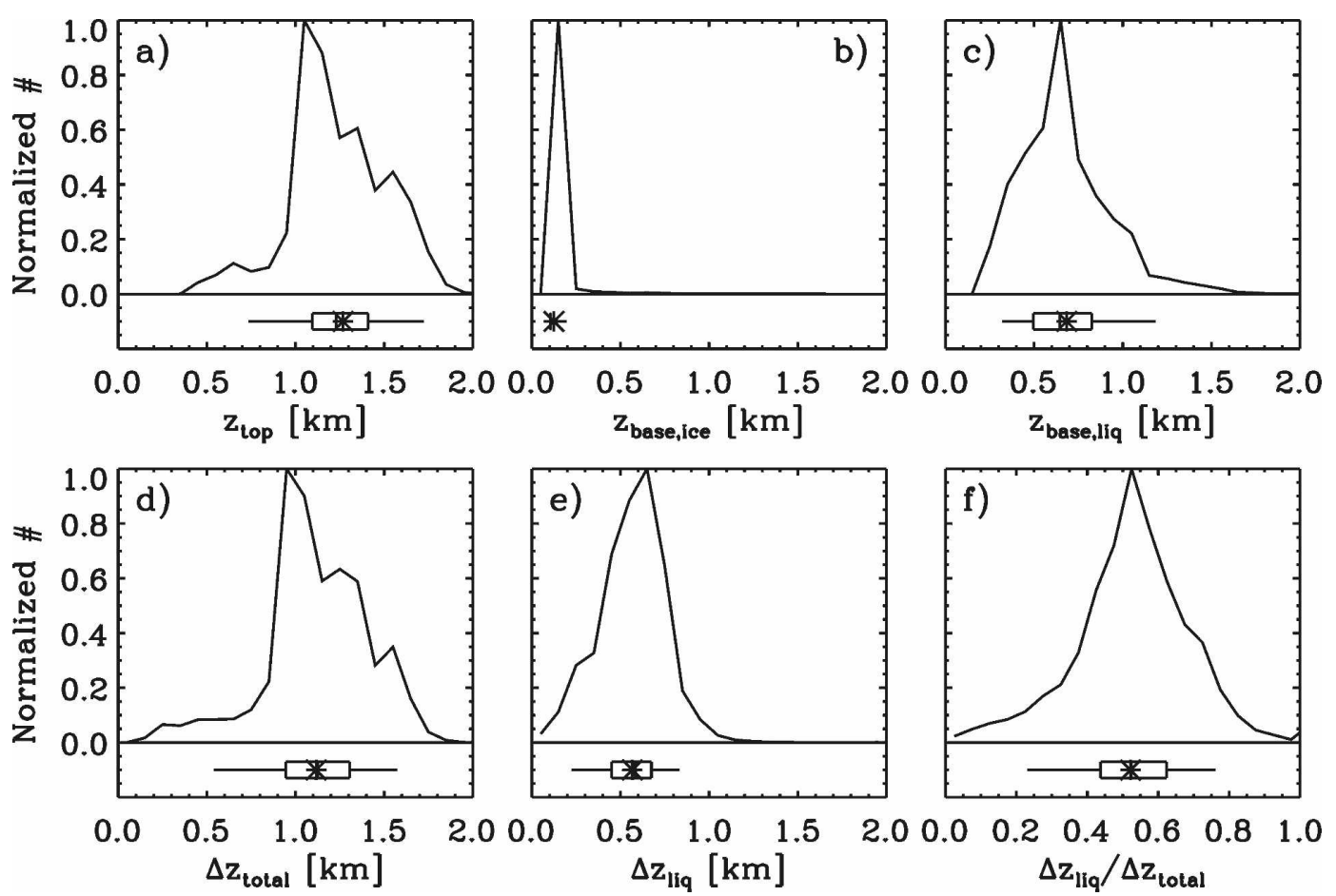

FIG. 6. Normalized distributions and statistics of mixed-phase cloud macrophysical properties: (a) cloud-top height, (b) cloud-base height including all precipitating ice, (c) base height of the cloud liquid component, (d) total cloud thickness including all precipitating ice, (e) total thickness of the cloud liquid layer, and (f) ratio of the liquid thickness to the total cloud thickness. Each distribution is normalized by its maximum value. The box-and-whisker plots provide the 5th, 25th, 50th, 75th, and 95th percentiles of the data and the symbol is the mean.

ticularly in the month of October (Shupe et al. 2006). In contrast, the LWP during MPACE was substantially larger than in the fall 1998 Arctic Ocean observations (Shupe et al. 2006). Furthermore, while airspace restrictions and horizontal inhomogeneity have made direct comparisons with aircraft observations difficult, McFarquhar et al. (2007) indicate a "typical" IWC of $0.01 \mathrm{~g} \mathrm{~m}^{-3}$ in these clouds, which is in reasonable qualitative agreement with the IWCs presented here (i.e., Table 1). Comparisons of ice particle size, on the contrary, have shown differences of about a factor of 2 , which may be due to differences in the assumed particle shapes and mass-to-area ratios.

Vertical air motions in these low-level mixed-phase clouds predominantly range from a lifting of $2.5 \mathrm{~m} \mathrm{~s}^{-1}$ to a falling of $1.5 \mathrm{~m} \mathrm{~s}^{-1}$ (Fig. 9a), with a median updraft velocity of $0.40 \mathrm{~m} \mathrm{~s}^{-1}$. Similar distributions are found for both height-resolved and layer-averaged datasets, indicating that the vertical motion structures are vertically coherent. The range of retrieved vertical velocities is similar to that observed in stratus by Paluch and Lenschow (1991) but somewhat smaller than that observed in marine fair-weather cumulus by Kollias et al. (2001). In addition, a comparison of vertical motion retrievals with aircraft in situ observations during MPACE shows generally good agreement in both magnitude and variability (Shupe et al. 2008). While the conclusion of a net lifting motion appears robust based on the agreement between, and expected uncertainties of, ground-based retrievals and aircraft observations, the cause of this net lifting is somewhat uncertain. First, the fact that vertical velocity is only estimated within liquid watercontaining clouds might bias the results toward a net updraft, while cloud-free conditions may be biased toward downward motion. Second, preliminary results using a regional model suggest that coastal effects of topography and changes in surface roughness may lead to a low-level convergence, and thus rising motion, near Barrow. Additional studies are required to further elucidate this net lifting motion.

Spectral analysis of many layer-averaged vertical velocity time series reveals energetically dominant scalesof-motion at $0.5-10-\mathrm{km}$ wavelengths. An estimate of the strength, or amplitude, of in-cloud circulations is made by taking one-half of the difference between the 95th and 5th percentiles of a 30-min $(\sim 20 \mathrm{~km})$ time series of layer-averaged vertical velocity data surrounding each point. Similarly, the difference between the 

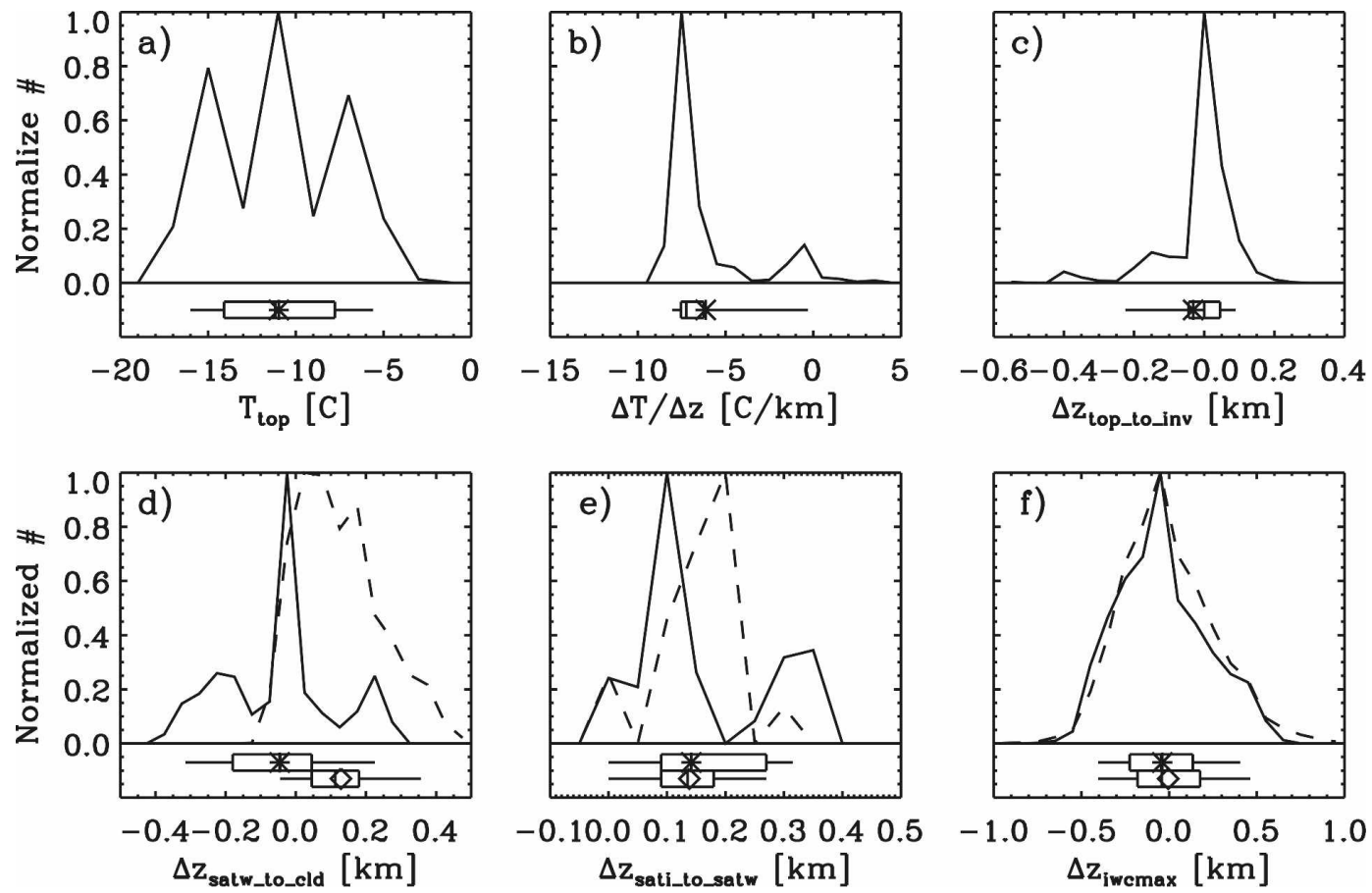

FIG. 7. As in Fig. 6, but for (a) cloud-top temperature, (b) in-cloud lapse rate, (c) vertical distance between the cloud-top height and the base of the temperature inversion, (d) vertical distance between the layer of water saturation and the cloud liquid top (solid, star) and bottom (dashed, diamond), (e) vertical distance between the levels of water and ice saturation at the cloud top (solid, star) and base (dashed, diamond), and (f) vertical distance between the base of the region of ice saturation and the level of maximum IWC (solid, star) and between the level of maximum IWC and the base of the cloud liquid (dashed, diamond). All data, except for the dashed curve in (f), are based on observations within $15 \mathrm{~min}$ of a radiosonde launch.

95th minus 50th and 50th minus 5th percentiles provides an estimate of the skewness of the vertical velocity distribution over the same 30-min window. According to these statistics, the average 30-min circulation strength is $\sim 0.7 \mathrm{~m} \mathrm{~s}^{-1}$ but can range from 0.3 to 1.0 $\mathrm{m} \mathrm{s}^{-1}$ (Fig. 9d). The skewness parameter is typically close to zero (Fig. 9e), indicating that, relative to the mean vertical motion, there is little preference toward stronger or narrower updrafts or downdrafts. However, due to the mean lifting motion, true downdrafts are limited in both time and space and are most often observed near the base of the cloud liquid.

A characteristic, layer-averaged ice particle terminal fall speed is computed by taking the reflectivityweighted mean Doppler velocity measurement and subtracting the retrieved layer-average vertical velocity. A typical ice particle fall speed is about $0.9 \mathrm{~m} \mathrm{~s}^{-1}$, although a substantial range is observed (Fig. 9c) based on the range of ice particle sizes and habits. The largest observed fall speeds are indicative of aggregation and riming of ice particles (e.g., Pruppacher and Klett 1978), which were observed to occur in mixed-phase clouds during MPACE (McFarquhar et al. 2007).
Turbulent dissipation rates range from $10^{-8}$ to $10^{-2}$ $\mathrm{m}^{2} \mathrm{~s}^{-3}$, with a mean value of nearly $10^{-3.7}$ and a median of $\sim 10^{-4} \mathrm{~m}^{2} \mathrm{~s}^{-3}$ (Fig. 9b). The retrieved range of $\varepsilon$ is consistent with the range observed by Gultepe and Starr (1995), while the largest retrieved values are similar to those reported for marine stratocumulus and Arctic stratus (Frisch and Clifford 1974; Brost et al. 1982; Curry et al. 1988; Kollias et al. 2001). Statistical comparisons of these retrievals with M-PACE in situ observations show reasonable agreement in most cases and suggest that the radar-based estimates might be biased low in some cases (Shupe et al. 2008).

\section{c. Relationships between parameters}

As suggested by the 28 October case (Figs. 3 and 5), there are several interesting relationships between vertical motions and cloud properties (Fig. 10). LWP, IWP, and $R_{\mathrm{ei}}$ increase as the updraft velocity increases. While the LWP is typically $\sim 100 \mathrm{~g} \mathrm{~m}^{-2}$ under neutral or downdraft conditions, the IWP is negligible. This behavior leads to the observation of generally high liquid fractions and to the interesting result that the liquid fraction actually decreases as the strength of the up- 

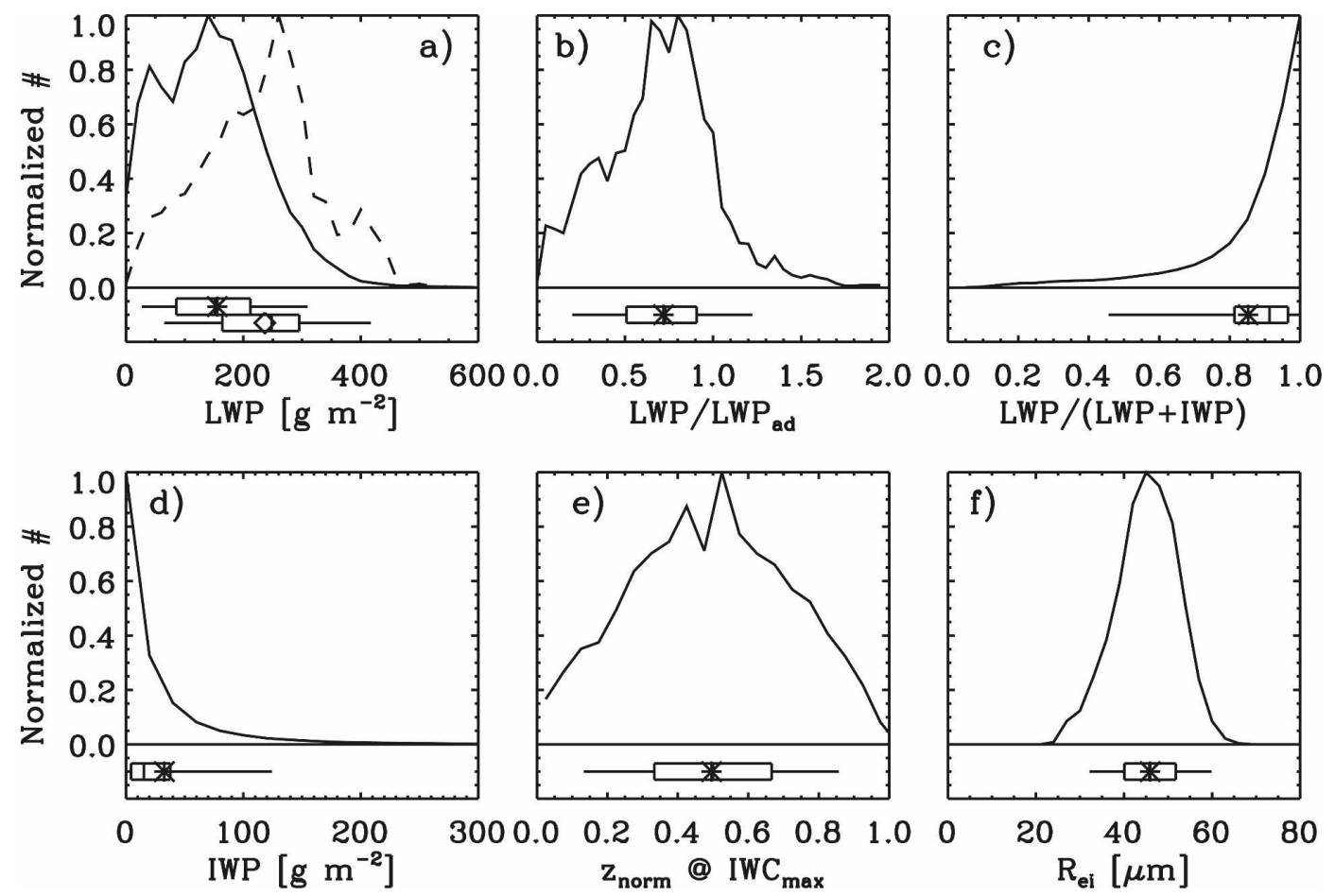

FIG. 8. As is Fig. 6, but for (a) liquid water path derived from microwave radiometer (line, star) and adiabatically (dash, diamond), (b) ratio of the observed LWP to the computed adiabatic LWP, (c) liquid fraction, or LWP/ (LWP + IWP), (d) ice water path, (e) normalized height within the total cloud system (liquid and ice, normalized from 0 to 1 ) at which the maximum ice water content occurs, and (f) vertically resolved ice particle effective radius.

draft increases. The LWP increases at a rate of $\sim 80 \mathrm{~g}$ $\mathrm{m}^{-2}\left(\mathrm{~m} \mathrm{~s}^{-1}\right)^{-1}$ on average, which is 3 times the average rate of ice mass increase with increasing vertical motion. There is a slight suggestion of a relationship between the vertical air motion and the ratio of LWP to adiabatic LWP, where stronger updraft conditions promote a more nearly adiabatic distribution of cloud liquid. Cloud liquid-layer thickness tends to increase as the vertical lifting motions increase, but there is only a weak relationship between cloud-top height and vertical motions. Strong updrafts $\left(>1 \mathrm{~m} \mathrm{~s}^{-1}\right)$ only occur for cloud-top heights above $1 \mathrm{~km}$, while weaker updrafts occur in clouds with any top height.

It is interesting to note the relationship between the derived vertical air motion and the radar measurements within the liquid-containing cloud volumes (Fig. 11). On average for these clouds, the atmosphere is vertically still at reflectivities near $-40 \mathrm{dBZ}$, but has progressively more updraft strength as reflectivity increases. The average updraft strength increases with reflectivity at a rate of $0.02 \mathrm{~m} \mathrm{~s}^{-1}(\mathrm{dBZ})^{-1}$ from $0 \mathrm{~m} \mathrm{~s}^{-1}$ at $-40 \mathrm{~dB} Z$. Vali et al. (1998) also observed a correlation between reflectivity and the updraft strength in drizzling stratus, which they suggested was solely due to the drizzle portion of the drop size distribution. Simi- larly, the mean Doppler velocity tends to decrease with updraft strength, in part because vertical velocity is one component of the measured Doppler velocity. Finally, the spectrum width tends to increase with updraft strength, a feature that is likely related to the formation and growth of particles in an updraft, which leads to a broader particle size distribution.

\section{A conceptual model of the cloud circulation process}

These observations of cloud properties and dynamical structures help to elucidate some of the important processes in action in Arctic autumn mixed-phase stratiform clouds. Although there are still substantial unknowns and other important factors determining the composition of these clouds, the following is a summary from the perspective of the ground-based sensors of the manner in which cloud-scale vertical motions affect the cloud life cycle. In particular, a small mesoscale cycle, consisting of a primary circulation on a scale of approx. 5-8 km from the radar's perspective, is described here, many details of which are illustrated in the conceptual model diagram in Fig. 12 and exhibited in the example case study in Fig. 5. The vertical-profiling, Eulerian per- 

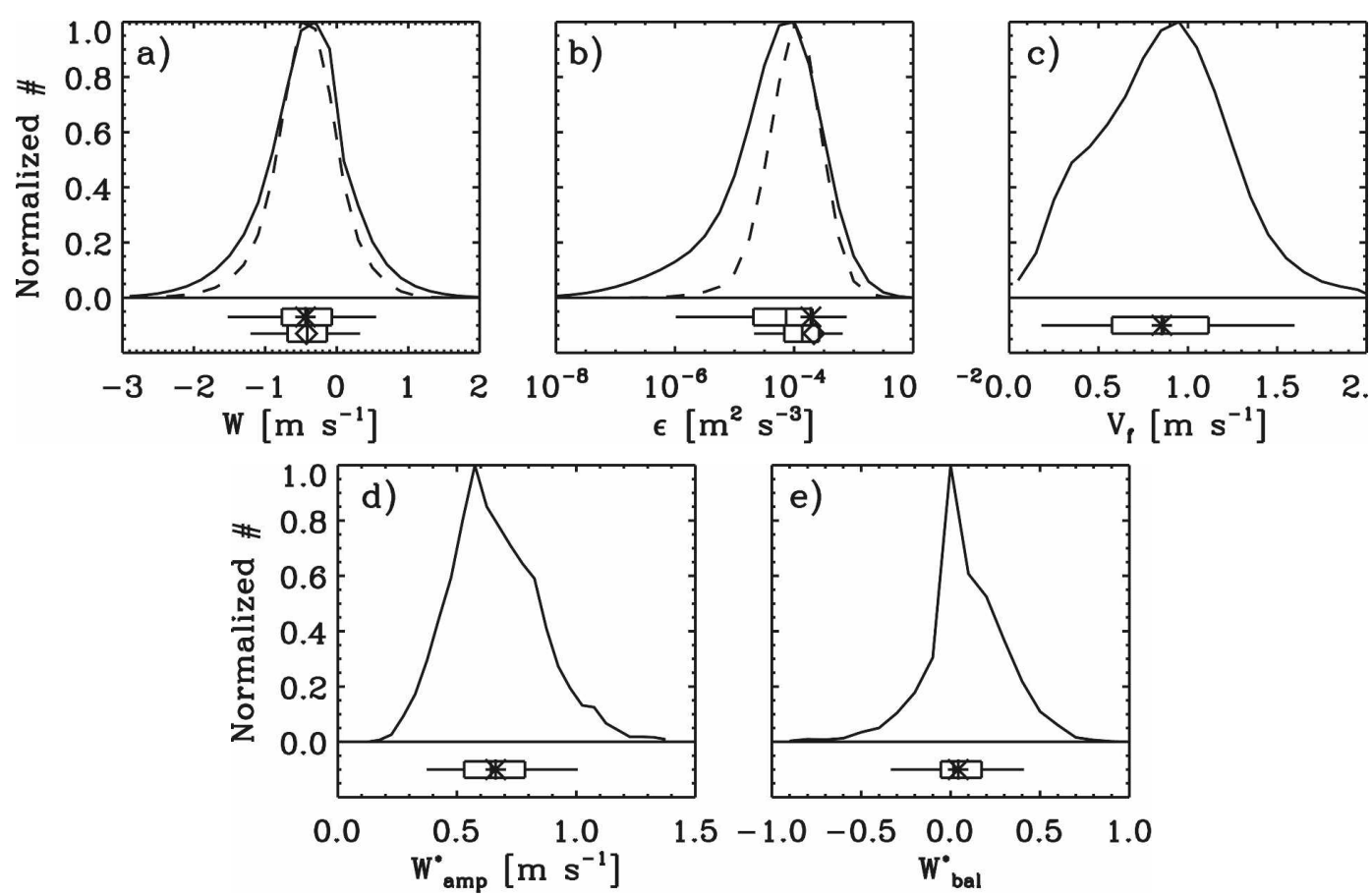

FIG. 9. As in Fig. 6, but for (a) vertically resolved (line, star) and layer-averaged (dash, diamond) vertical velocity, (b) vertically resolved (line, star) and layer-averaged (dash, diamond) turbulent dissipation rate, (c) ice particle fall speed, which has been corrected for vertical air motions, (d) amplitude of vertical velocity features (95th minus 5th percentiles over 30-min window of vertical velocities), and (e) balance of updraft and downdraft features relative to the mean vertical motion (difference between 95th minus 50th and 50th minus 5th percentiles over a 30-min window of vertical velocities).

spective that was used to develop this conceptual model is important to keep in mind; the horizontal extent of the cloud circulations is observed here as the cloud elements advect over the observation site. It is assumed that the cloud circulations are static relative to the advecting cloud system; that is, the time scales associated with these evolving circulations (at least tens of minutes) are significantly longer than the observation time (seconds). Although these time scales are not specifically known, some assertions regarding the relative timing of processes are made below.

At the onset of a broad updraft feature, there remains some residual liquid water from the previous cycle, but little cloud ice. Liquid water production commences with the updraft as moist air is lifted to saturation and condenses, quickly increasing the cloud liquid water path toward its adiabatic value. Prior to this updraft, the liquid water is subadiabatic. As a result of the vertical motions and liquid condensation, the cloud top lifts moderately, with inertia carrying the cloud top above the level of saturation. The lifting motions are limited in the vertical by the stabilizing effects of a temperature inversion, which is usually associated with the cloud top.
Cloud ice production occurs simultaneously with the liquid water, likely via ice initiation processes that require the presence of liquid water (e.g., Rauber and Tokay 1991). Profiles of ice water content, derived from radar reflectivity, suggest that at least some ice crystals initiate near the cloud top and that the ice grows as it falls through the cloud liquid. In support of this observation, Hobbs and Rangno (1985) indicate that the cloud-top region is a primary source of ice crystal formation. Furthermore, the general absence of ice crystals in the absence of strong and persistent updraft conditions suggests that ice initiation in these clouds requires a significant supersaturation with respect to ice (e.g., Pruppacher and Klett 1978) in order to activate the limited number of IFN.

As both phases grow in an updraft, the ratio of total liquid to total ice in the cloud layer decreases, predominantly because the cloud was nearly all liquid prior to the updraft. In terms of total mass, there is generally more liquid water mass produced in the broad updraft than ice water mass. Although the mesoscale circulation is largely responsible for the amount of condensate at any given time, there are smaller-scale turbulent motions that impact the local cloud variability. Superim- 
TABLE 1. Summary statistics for derived cloud properties. The range is considered from the 5th to 95th percentiles. Parameters with an * are based on layer-averaged data. Abbreviations include the following: sat = level of saturation, liq $=$ the liquid cloud layer, and norm $=$ normalized height ( 0 is the base of the cloud ice and 1 is the cloud top).

\begin{tabular}{|c|c|c|c|c|c|}
\hline Parameter (units) & No. of obs & Mean & Std dev & Median & Range \\
\hline Cloud-top height, $z_{\text {top }}(\mathrm{km})$ & $1.7 \times 10^{5}$ & 1.27 & 0.36 & 1.23 & $0.74-1.73$ \\
\hline Base of cloud ice, $z_{\text {base,ice }}(\mathrm{km})$ & $1.7 \times 10^{5}$ & 0.12 & 0.10 & 0.11 & $0.11-0.20$ \\
\hline Base of cloud liquid, $z_{\text {base,liquid }}(\mathrm{km})$ & $1.7 \times 10^{5}$ & 0.68 & 0.30 & 0.65 & $0.32-1.19$ \\
\hline Liq + ice thickness, $\Delta z_{\text {total }}(\mathrm{km})$ & $1.6 \times 10^{5}$ & 1.12 & 0.29 & 1.13 & $0.54-1.58$ \\
\hline Liquid thickness, $\Delta z_{\text {liquid }}(\mathrm{km})$ & $1.6 \times 10^{5}$ & 0.57 & 0.19 & 0.59 & $0.23-0.83$ \\
\hline Liq/total thickness, $\Delta z_{\text {liquid }} / \Delta z_{\text {total }}$ & $1.6 \times 10^{5}$ & 0.52 & 0.16 & 0.52 & $0.23-0.76$ \\
\hline Cloud-top temperature, $T_{\text {top }}\left({ }^{\circ} \mathrm{C}\right)$ & $5.1 \times 10^{3}$ & -11.2 & 3.4 & -11.2 & $-16.2--5.7$ \\
\hline In-cloud lapse rate, $\Delta T / \Delta z\left({ }^{\circ} \mathrm{C} \mathrm{km}^{-1}\right)$ & $5.1 \times 10^{3}$ & -6.0 & 2.6 & -7.2 & $-8.0--0.3$ \\
\hline Cloud top to inversion base, $\Delta z_{\mathrm{ztop} \text {,inv }}(\mathrm{km})$ & $4.3 \times 10^{3}$ & -0.02 & 0.11 & 0.00 & $-0.23-0.09$ \\
\hline Sat to cloud top, $\Delta z_{\text {satw-ztop }}(\mathrm{km})$ & $3.2 \times 10^{3}$ & -0.03 & 0.14 & -0.04 & $-0.31-0.23$ \\
\hline Sat to liq base, $\Delta z_{\text {satw-zbase,liq }}(\mathrm{km})$ & $3.2 \times 10^{3}$ & 0.13 & 0.12 & 0.12 & $-0.04-0.36$ \\
\hline Ice to liq sat at top, $\Delta z_{\text {sati-satw_top }}(\mathrm{km})$ & $3.2 \times 10^{3}$ & 0.14 & 0.10 & 0.09 & $0.00-0.32$ \\
\hline Liq to ice sat at base, $\Delta z_{\text {satw-sati_base }}(\mathrm{km})$ & $3.2 \times 10^{3}$ & 0.14 & 0.06 & 0.14 & $0.00-0.27$ \\
\hline Ice sat to max IWC, $\Delta z_{\text {sati_maxiwc }}(\mathrm{km})$ & $5.1 \times 10^{3}$ & -0.04 & 0.24 & -0.09 & $-0.40-0.41$ \\
\hline Liq base to max IWC, $\Delta z_{\text {zbaseliq-maxiwc }}(\mathrm{km})$ & $1.7 \times 10^{4}$ & -0.01 & 0.28 & -0.04 & $-0.41-0.46$ \\
\hline Ice effective radius, $R_{\mathrm{ei}}(\mu \mathrm{m})$ & $8.6 \times 10^{6}$ & 46 & 8 & 46 & $32-60$ \\
\hline Ice water content, IWC $\left(\mathrm{mg} \mathrm{m}^{-3}\right)$ & $8.1 \times 10^{6}$ & 23 & 47 & 6 & $0.2-100$ \\
\hline Norm height of max IWC, $z_{\text {norm }}$ at $\mathrm{IWC}_{\max }$ & $1.6 \times 10^{5}$ & 0.50 & 0.22 & 0.50 & $0.13-0.86$ \\
\hline Ice water path, IWP $\left(\mathrm{g} \mathrm{m}^{-2}\right)$ & $1.7 \times 10^{5}$ & 33 & 54 & 15 & $0.1-120$ \\
\hline Liquid water path, LWP $\left(\mathrm{g} \mathrm{m}^{-2}\right)$ & $1.7 \times 10^{5}$ & 156 & 88 & 150 & $27-310$ \\
\hline Adiabadicity, LWP/LWP & $5.1 \times 10^{3}$ & 0.77 & 0.34 & 0.76 & $0.22-1.42$ \\
\hline Liquid fraction, LWP/(LWP + IWP) & $1.7 \times 10^{5}$ & 0.85 & 0.17 & 0.91 & $0.46-1.00$ \\
\hline Ice fall speed, $V_{f}\left(\mathrm{~m} \mathrm{~s}^{-1}\right)$ & $1.6 \times 10^{5}$ & 0.85 & 0.65 & 0.86 & $0.18-1.60$ \\
\hline Vertical velocity, $W\left(\mathrm{~m} \mathrm{~s}^{-1}\right)$ & $3.4 \times 10^{6}$ & -0.44 & 0.63 & -0.40 & $-1.53-0.55$ \\
\hline Vertical velocity, $W^{*}\left(\mathrm{~m} \mathrm{~s}^{-1}\right)$ & $1.7 \times 10^{5}$ & -0.42 & 0.47 & -0.41 & $-1.21-0.33$ \\
\hline Amplitude of vertical velocity, $W_{\text {amp }}^{*}\left(\mathrm{~m} \mathrm{~s}^{-1}\right)$ & $2.7 \times 10^{5}$ & 0.66 & 0.19 & 0.64 & $0.37-1.01$ \\
\hline "Skewness" of vertical velocity, $W_{\text {bal }}^{*}\left(\mathrm{~m} \mathrm{~s}^{-1}\right)$ & $3.1 \times 10^{5}$ & 0.04 & 0.22 & 0.02 & $-0.33-0.41$ \\
\hline Turbulent dissipation rate, $\varepsilon\left(\mathrm{m}^{2} \mathrm{~s}^{-3}\right)$ & $8.2 \times 10^{6}$ & $1.9 \times 10^{4}$ & $3.6 \times 10^{4}$ & $7.3 \times 10^{5}$ & $1.0 \times 10^{6}-7.6 \times 10^{4}$ \\
\hline Turbulent dissipation rate, $\varepsilon^{*}\left(\mathrm{~m}^{2} \mathrm{~s}^{-3}\right)$ & $1.6 \times 10^{5}$ & $2.1 \times 10^{4}$ & $2.7 \times 10^{4}$ & $1.4 \times 10^{4}$ & $2.1 \times 10^{5}-6.5 \times 10^{4}$ \\
\hline
\end{tabular}

posed on the larger circulation are motions with 0.5 - to $1-\mathrm{km}$ wavelengths that lead to a pulse-like behavior observed in both liquid and ice condensate but are most evident in the ice properties.

As the magnitude of the updraft weakens, the net production of cloud condensate stops and the LWP, IWP, and ice particle sizes decline. It is assumed that this decline is consistent with a moisture profile that becomes subsaturated with respect to water, although there are insufficient radiosonde measurements sampling the near-neutral and weak downdraft conditions to verify this assumption. The cloud top descends and the cloud liquid again becomes subadiabatic as the rising motions subside, and dry air from above cloud top is likely entrained (e.g., Paluch and Lenschow 1991) leading to cloud-top evaporation.

The fact that the cycle in cloud ice coincides closely with that of the vertical motions, in spite of the continued presence of cloud liquid in the vertical column, suggests that there must be some degree of vertical stratification in the phases when an updraft is not present. That is, in the absence of an updraft new ice particle initiation halts and the limited number of ice crystals grow quickly to large sizes and fall out, leaving a relatively ice-free liquid cloud layer near the cloud top, a structure that is supported by aircraft measurements in these same clouds (McFarquhar et al. 2007). Moreover, the liquid appears to support the rapid fallout of ice particles by riming (McFarquhar et al. 2007), which increases the particle fall speeds and hastens the particle removal. The liquid layer is therefore diminished more slowly than it would be in the presence of cloud ice. Similarly, the falling cloud ice does not continue to grow by deposition much beyond the base of the cloud liquid because it falls from the region where the evaporating liquid maintains a relatively high supersaturation with respect to ice. Thus, by the end of the small mesoscale cycle, most, if not all, of the cloud ice has fallen out and/or evaporated, leaving behind a residual layer of cloud liquid that would likely disappear in time were the parcel not to undergo another updraft. The persistence of cloud liquid, even in the periodic presence of cloud ice, and its overall dominance in these clouds, implies strong water vapor fluxes 


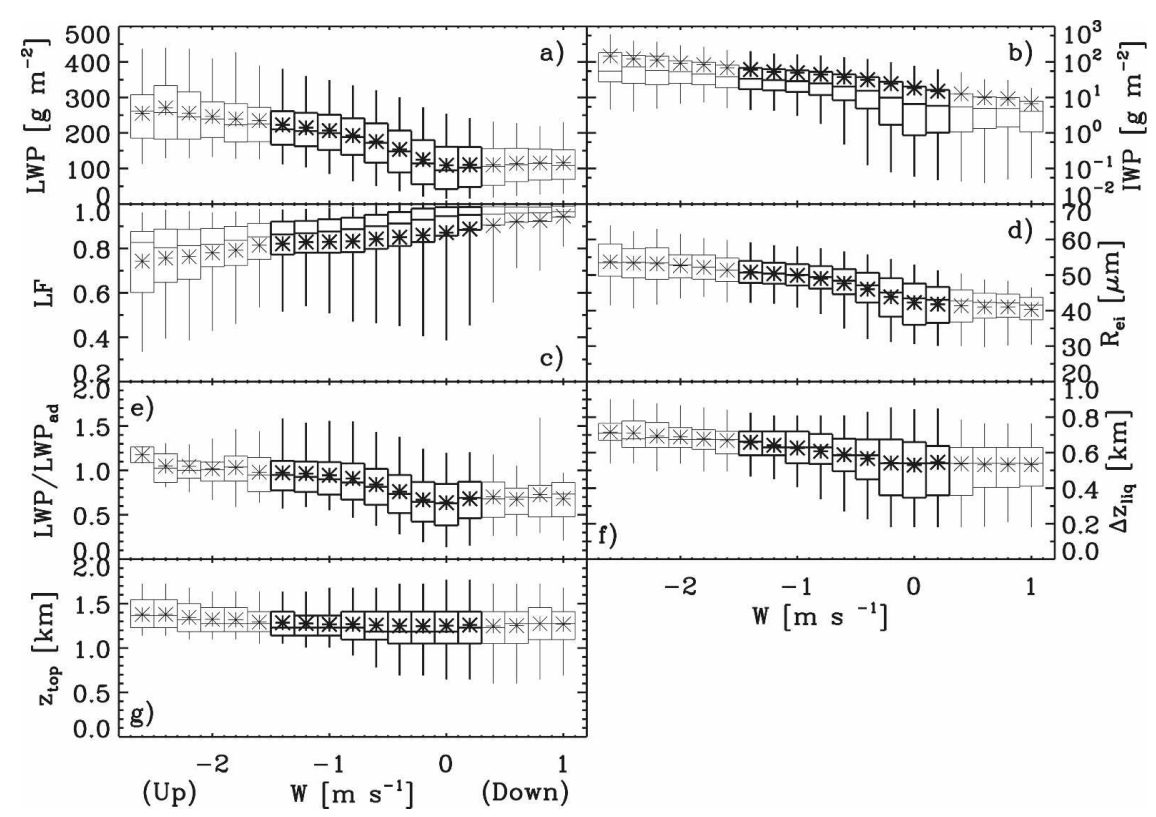

FIG. 10. Relationships between vertical velocity and (a) LWP, (b) IWP, (c) liquid fraction, (d) ice particle effective radius, (e) adiabadicity ( $\mathrm{LWP}_{\text {meas }} / \mathrm{LWP}_{\text {adiabatic }}$ ), (f) thickness of cloud liquid layer, (g) cloud-top height, and (h) cloud-top temperature. Box-and-whisker diagrams (5th, 25th, 50th, 75th, and 95th percentiles and the mean) are given for each parameter in 0.2 $\mathrm{m} \mathrm{s}^{-1}$-wide bins of vertical velocities. The bold box-and-whisker diagrams constitute approximately the middle $90 \%$ of the vertical velocity data.

and limited ice-forming nuclei concentrations (Pinto 1998; Korolev and Isaac 2003).

Fallout of ice particles from the liquid cloud base effectively removes moisture from the cloud layer; however, sublimation appears to be more important than precipitation to the surface as a sink for the falling ice. Cloud ice water content decreases with decreasing height starting at approximately the base of the cloud liquid, suggesting that both the initiation and production of ice are closely linked to the presence of cloud water and that much of the falling ice mass sublimates prior to reaching the ground. Indeed, observations of precipitation accumulation at the surface are very small for these clouds. The lack of precipitation reaching the surface indicates that the moisture lost from the cloud layer is largely recycled into the subcloud atmosphere

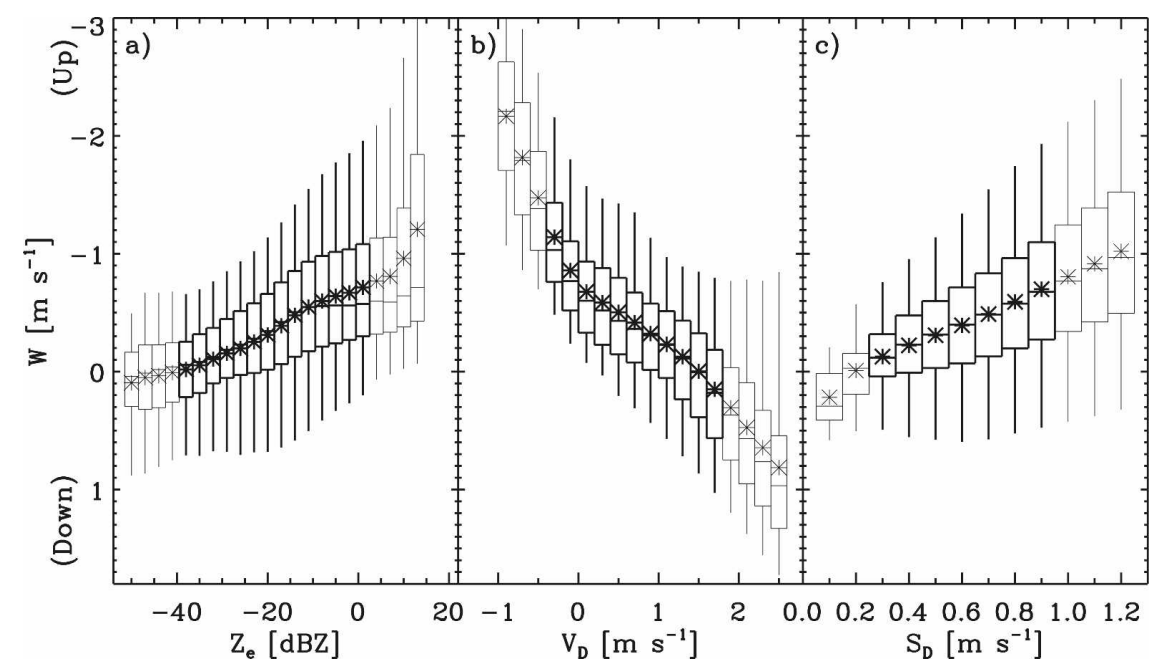

FIG. 11. As in Fig. 10, but for vertical velocity as a function of (a) radar reflectivity, (b) mean Doppler velocity, and (c) Doppler spectrum width. 

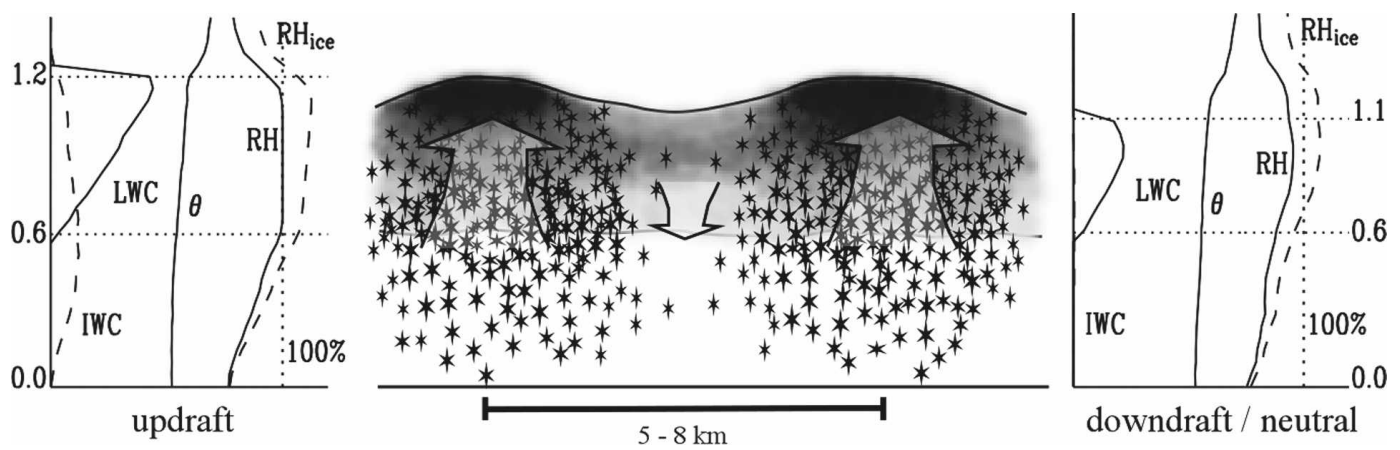

FIG. 12. A conceptual model illustrating the interdependence of cloud microphysics, thermodynamic profiles, and vertical motions in autumn Arctic mixed-phase stratiform clouds observed near the coast of Alaska. The bounding plots contain generalized profiles of liquid and ice water content, potential temperature, and relative humidity with respect to both liquid and ice. Horizontal dashed lines are the top and bottom of the cloud liquid (shown at typical heights in $\mathrm{km}$ ), while the vertical dashed line is $\mathrm{RH}=100 \%$. (left) The conditions that occur in a broad updraft and (right) conditions under neutral or downward motion. (middle) The level of shading represents the amount of liquid water mass, the density of stars indicates the amount of ice mass, arrows indicate general air motions, and a horizontal length scale is provided.

and may be available for cloud formation in subsequent updrafts. Turbulence driven by cloud-top radiative cooling may be responsible for mixing through much of the boundary layer (Curry et al. 1988; Paluch and Lenschow 1991; Pinto 1998; Lothon et al. 2005), while ice sublimation below cloud base might support or damp this mixing depending on the height at which sublimation occurs (e.g., Feingold et al. 1996). Turbulent dissipation rates associated with these clouds typically have uniform variability from cloud top to the surface, which is consistent with mixing in the boundary layer. Furthermore, thermodynamic profiles during MPACE often reveal a constant potential temperature below the liquid cloud base and a constant equivalent potential temperature extending up to the cloud top. Together these indicate that the top of the boundary layer is often at the cloud top and that the boundary layer is neutral to moist adiabatic lifting. Thus, at least in some cases, circulations leading to cloud formation originate from near the surface and can reinject the moisture from subcloud ice sublimation into the cloud layer.

The persistent liquid and absence of cloud ice between strong updrafts provides a constraint on the time scale on which a given air/cloud parcel, in a Lagrangian sense, undergoes a full cycle. Specifically, a parcel that is currently in a mean neutral or downdraft state must have previously been in an updraft state at some time that is constrained to lie between the liquid evaporation time and the ice fallout time. A typical fall speed for the ice is $\sim 0.9 \mathrm{~m} \mathrm{~s}^{-1}$ (Fig. 9c). Thus, for a typical cloud liquid layer depth of approximately $0.7 \mathrm{~km}$, the fallout time is about $13 \mathrm{~min}$. Computation of the upper time constraint due to evaporation of the liquid layer is much more difficult because the time evolution and magnitude of the droplet microphysics (size and/or concentration) and the atmospheric moisture profile are unknown in this case. For typical cloud droplet sizes, the subsaturation must be quite small (RH on the order of $99.9 \%$ ) in order for the liquid to persist longer than the ice fallout time. This small degree of subsaturation, as an average over a few minutes, is consistent with the turbulent state during these relatively quiescent, interupdraft periods that consists of weak, turbulent up- and downdrafts. Thus, it is clear that a given parcel goes through a full cycle in no less than about 26 min (which is twice the estimated ice fallout time) and that the absence of strong, persistent downdrafts allows for slow liquid water evaporation.

This description is limited to cloud and atmosphere properties that were monitored from the surface near the northern Alaskan coast during MPACE. Other properties, including the concentration and composition of IFN and the heat and moisture forcing mechanisms for forming these clouds, are clearly influential on the cloud properties, the ratio of cloud phases, and the overall cloud life cycle. For example, under conditions with higher IFN concentrations near cloud top than were present at MPACE, it is possible that relatively more ice growth would occur, leading to reduced liquid-to-ice ratios and possibly to full glaciation between updrafts. A full picture of the cloud life cycle requires explicit knowledge of these additional properties.

\section{Summary}

The pivotal role of vertical motions in Arctic mixedphase stratiform clouds is examined using measure- 
ments from the Mixed-Phase Arctic Cloud Experiment, which took place in and around Barrow, Alaska, in autumn 2004. Retrievals of cloud macrophysical, microphysical, and dynamical properties from radar, lidar, and microwave radiometer measurements are used to characterize these clouds and to provide insight into the effects of vertical motions on the cloud properties and the manner in which they support and drive the cloudscale processes that lead to long-lived, mixed-phase stratiform clouds.

Single-layer, low-level mixed-phase stratiform clouds in the coastal western Arctic autumn are typically topped by a 400-700-m layer of cloud liquid from which ice particles form and fall, with an equally thick layer of ice precipitation below the cloud base reaching down to near the surface. Cloud top is usually between 1 and 1.5 $\mathrm{km}$ and most often at, or just below, the base of a temperature inversion, with a range of cloud temperatures of $-18^{\circ}$ to $-4^{\circ} \mathrm{C}$. Cloud liquid water path (typically $\left.50-300 \mathrm{~g} \mathrm{~m}^{-2}\right)$ is substantially larger than cloud ice water path $\left(<100 \mathrm{~g} \mathrm{~m}^{-2}\right)$, leading to mixed-phase cloud layers that are usually at least $85 \%$ liquid water. It appears that autumn mixed-phase clouds occurring out over the Arctic Ocean are somewhat less liquid dominated (Shupe et al. 2006). Cloud ice mass increases as ice falls from near the cloud top until near the base of the cloud liquid, below which it sublimates prior to reaching the surface. Vertical motions associated with these clouds range from $2.5 \mathrm{~m} \mathrm{~s}^{-1}$ upward to $1.5 \mathrm{~m} \mathrm{~s}^{-1}$ downward, with an average updraft of $\sim 0.4 \mathrm{~m} \mathrm{~s}^{-1}$, which may be influenced by coastal features and/or the fact that vertical motions are only derived within cloud layers. Over time periods on the order of one-half hour, the amplitude of vertical velocity features is, on average, $0.7 \mathrm{~m} \mathrm{~s}^{-1}$, with the updrafts and downdrafts (relative to the mean motion) having comparable size and strength. Turbulent dissipation rates in the range of $10^{-6}$ to $10^{-3} \mathrm{~m}^{2} \mathrm{~s}^{-3}$ are observed.

Some crucial cloud and atmosphere properties cannot currently be derived from the present suite of instruments in operation at the NSA site, and therefore a complete understanding of the cloud circulation and microphysical processes is lacking. The most crucial gaps are the vertical distribution of cloud liquid droplet size and water content (although adiabadicity can sometimes be assumed), the time evolution of atmospheric moisture profiles, the spatial distribution of dynamical-microphysical processes, and the aerosol concentration and composition. Explicit knowledge of these properties would aid in the understanding of the cloud life cycle and the manner in which it evolves with season.

In spite of these deficits, the ground-based observa- tions from MPACE help to clarify some aspects of the mixed-phase cloud life cycle. Cloud condensate in both phases increases in response to updrafts. This is in contrast to drizzling midlatitude stratus wherein only the drizzle content increases in an updraft but the cloud water content apparently does not (Vali et al. 1998). Although the total mass of cloud liquid in Arctic mixedphase clouds increases more than that of cloud ice in a mesoscale updraft, the ratio of cloud liquid to ice decreases. This behavior is predominantly due to the persistence of at least a minimal amount of liquid water between updrafts while the ice almost completely falls from the layer and sublimates. The persistence of cloud liquid throughout the mesoscale circulations, and the dominance of liquid in these clouds, is likely caused by a limited supply of ice-forming nuclei and a plentiful supply of water vapor, which may be recycled through multiple circulations. Furthermore, the time scale associated with these motions is constrained to be longer than the time for ice fallout $(\sim 26 \mathrm{~min})$ but shorter than the time for the cloud liquid to evaporate.

The important scales-of-variability in Arctic mixedphase stratiform clouds for local cloud maintenance are typically on the order of $0.5-10 \mathrm{~km}$. At these scales, cloud circulations provide the driving force for cloud formation and persistence. In particular, cloud microphysical processes such as initiation, growth, fallout, and evaporation are closely linked to the vertical motions and contribute strongly to the partitioning of cloud phase. The cloud phase balance, in turn, establishes the cloud radiative, microphysical, and hydrologic properties. Global, regional, and even some mesoscale models are currently unable to resolve processes that occur on these scales, and therefore have a limited ability to accurately represent the persistence of Arctic mixed-phase stratiform clouds.

Although it is apparent that cloud-scale vertical motions are integral in shaping the phase partitioning and microphysical composition of mixed-phase clouds, the source of these vertical motions themselves is not as clear. Vertical motions are impacted by cloud-top radiative cooling, wind shear, surface turbulent heat fluxes (e.g., Rauber and Tokay 1991; Pinto 1998), latent cooling due to evaporation (Harrington and Olsson 2001), and the entrainment of dry air at cloud top (Paluch and Lenschow 1991). The balance and relative importance of these forcing mechanisms in determining cloud-scale vertical motions and cloud longevity is likely variable in time and space. Issues concerning the forcing of cloud motions in Arctic mixed-phase stratiform clouds are a logical extension of this analysis and will be addressed in future studies. 
Acknowledgments. This research was supported by the Office of Science (BER), U.S. Department of Energy, Grant DE-FG02-05ER63965. All datasets were obtained from the ARM data archives. Thanks to the MPACE team and ARM Program for collecting a wellfocused mixed-phase cloud dataset.

\section{REFERENCES}

Boucher, O., H. Le Treut, and M. B. Baker, 1995: Precipitation and radiation modeling in a general circulation model: Introduction of cloud microphysical processes. J. Geophys. Res., 100, 16 395-16 414.

Brost, R. A., J. C. Wyngaard, and D. H. Lenschow, 1982: Marine stratocumulus layers. Part II: Turbulence budgets. J. Atmos. Sci., 39, 818-836.

Curry, J. A., 1986: Interactions among turbulence, radiation, and microphysics in Arctic stratus clouds. J. Atmos. Sci., 43, 90106.

_ structure of the summertime Arctic cloudy boundary layer. Quart. J. Roy. Meteor. Soc., 114, 715-746.

Eloranta, E. W., 2005: High spectral resolution lidar. Lidar: Range-Resolved Optical Remote Sensing of the Atmosphere, C. Weitkamp, Ed., Springer-Verlag, 143-163.

Feingold, G., B. Stevens, W. R. Cotton, and A. S. Frisch, 1996: The relationship between drop in-cloud residence time and drizzle production in numerically simulated stratocumulus clouds. J. Atmos. Sci., 53, 1108-1122.

Frisch, A. S., and S. F. Clifford, 1974: A study of convection capped by a stable layer using Doppler radar and acoustic echo sounders. J. Atmos. Sci., 31, 1622-1628.

, C. W. Fairall, and J. B. Snider, 1995: Measurements of stratus cloud and drizzle parameters in ASTEX with a $\mathrm{K}_{\alpha}$-band Doppler radar and a microwave radiometer. J. Atmos. Sci., 52, 2788-2799.

Fu, Q., 1996: An accurate parameterization of the solar radiative properties of cirrus clouds for climate models. J. Climate, 9, 2058-2082.

Gregory, D., and D. Morris, 1996: The sensitivity of climate simulations to the specification of mixed phase clouds. Climate Dyn., 12, 641-651.

Gultepe, I., and D. O'C. Starr, 1995: Dynamical structure and turbulence in cirrus clouds: Aircraft observations during FIRE. J. Atmos. Sci., 52, 4159-4182.

Harrington, J. Y., and P. Q. Olsson, 2001: On the potential influence of ice nuclei on surface-forced marine stratocumulus cloud dynamics. J. Geophys. Res., 106, 27 473-27 484.

—, T. Reisen, W. R. Cotton, and S. M. Kreidenweis, 1999: Cloud resolving simulations of Arctic stratus. Part II: Transition-season clouds. Atmos. Res., 51, 45-75.

Herman, G., and R. Goody, 1976: Formation and persistence of summertime Arctic stratus clouds. J. Atmos. Sci., 33, 15371553.

Heymsfield, A. J., 1975: Cirrus uncinus generating cells and the evolution of cirriform clouds. Part II: The structure and circulations of the cirrus uncinus generating head. J. Atmos. Sci., 32, 809-819.

, L. M. Miloshevich, A. Slingo, K. Sassen, and D. O'C. Starr, 1991: An observational and theoretical study of highly supercooled altocumulus. J. Atmos. Sci., 48, 923-945.
Hobbs, P. V., and A. L. Rangno, 1985: Ice particle concentrations in clouds. J. Atmos. Sci., 42, 2523-2549.

Hogan, R. J., P. R. Field, A. J. Illingworth, R. J. Cotton, and T. W. Choularton, 2002: Properties of embedded convection in warm-frontal mixed-phase cloud from aircraft and polarimetric radar. Quart. J. Roy. Meteor. Soc., 128, 451-476.

$\longrightarrow$, P. N. Francis, H. Flentje, A. J. Illingworth, M. Quante, and J. Pelon, 2003a: Characteristics of mixed-phase clouds. I: Lidar, radar, and aircraft observations from CLARE'98. Quart. J. Roy. Meteor. Soc., 129, 2089-2116.

— A. J. Illingworth, E. J. O'Connor, and J. P. V. Poiares Baptista, 2003b: Characteristics of mixed-phase clouds. II: A climatology from ground-based lidar. Quart. J. Roy. Meteor. Soc., 129, 2117-2134.

-, M. P. Mittermaier, and A. J. Illingworth, 2006: The retrieval of ice water content from radar reflectivity factor and temperature and its use in evaluating a mesoscale model. J. Appl. Meteor. Climatol., 45, 301-317.

Intrieri, J. M., M. D. Shupe, T. Uttal, and B. J. McCarty, 2002: An annual cycle of Arctic cloud characteristics observed by radar and lidar at SHEBA. J. Geophys. Res., 107, 8030, doi:10.1029/ 2000JC000423.

Jiang, H., W. R. Cotton, J. O. Pinto, J. A. Curry, and M. J. Weissbluth, 2000: Cloud resolving simulations of mixed-phase Arctic stratus observed during BASE: Sensitivity to concentration of ice crystals and large-scale heat and moisture advection. J. Atmos. Sci., 57, 2105-2117.

Kollias, P., B. A. Albrecht, R. Lhermitte, and A. Savtchenko, 2001: Radar observations of updrafts, downdrafts, and turbulence in fair-weather cumuli. J. Atmos. Sci., 58, 1750-1766.

— E. E. Clothiaux, M. A. Miller, E. P. Luke, K. L. Johnson, K. P. Moran, K. B. Widener, and B. A. Albrecht, 2007: The Atmospheric Radiation Measurement Program cloud profiling radars: Second-generation sampling strategies, processing, and cloud data products. J. Atmos. Oceanic Technol., 24, 1199-1214.

Korolev, A., and G. Isaac, 2003: Phase transformation of mixedphase clouds. Quart. J. Roy. Meteor. Soc., 129, 19-38.

- , and - 2006: Relative humidity in liquid, mixed-phase, and ice clouds. J. Atmos. Sci., 63, 2865-2880.

,-- , S. G. Cober, J. W. Strapp, and J. Hallett, 2003: Microphysical characterization of mixed-phase clouds. Quart. J. Roy. Meteor. Soc., 129, 39-65.

Liljegren, J. C., E. E. Clothiaux, G. G. Mace, S. Kato, and X. Dong, 2001: A new retrieval for cloud liquid water path using a ground-based microwave radiometer and measurements of cloud temperature. J. Geophys. Res., 106, 14 485-14 500.

Lothon, M., D. H. Lenschow, D. Leon, and G. Vali, 2005: Turbulence measurements in marine stratocumulus with airborne Doppler radar. Quart. J. Roy. Meteor. Soc., 131, 2063-2080.

Matrosov, S. Y., A. V. Korolev, and A. J. Heymsfield, 2002: Profiling cloud ice mass and particle characteristic size from Doppler radar measurements. J. Atmos. Oceanic Technol., 19, 1003-1018.

McFarquhar, G. M., and S. G. Cober, 2004: Single-scattering properties of mixed-phase Arctic clouds at solar wavelengths: Impacts on radiative transfer. J. Climate, 17, 3799-3813.

—, G. Zhang, M. R. Poellot, G. L. Kok, R. McCoy, T. Tooman, A. Fridlind, and A. J. Heymsfield, 2007: Ice properties of single-layer stratocumulus during the Mixed-Phase Arctic Cloud Experiment: 1. Observations. J. Geophys. Res., 112, D24201, doi:10.1029/2007JD008633.

Moran, K. P., B. E. Martner, M. J. Post, R. A. Kropfli, D. C. 
Welsh, and K. B. Widener, 1998: An unattended cloudprofiling radar for use in climate research. Bull. Amer. Meteor. Soc., 79, 443-455.

Morrison, H., J. A. Curry, M. D. Shupe, and P. Zuidema, 2005a: A new double-moment microphysics parameterization for application in cloud and climate models. Part II: Single-column modeling of Arctic clouds. J. Atmos. Sci., 62, 1678-1693.

— M. D. Shupe, J. O. Pinto, and J. A. Curry, 2005b: Possible roles of ice nucleation mode and ice nuclei depletion in the extended lifetime of Arctic mixed-phase clouds. Geophys. Res. Lett., 32, L18801, doi:10.1029/2005GL023614.

Olsson, P. Q., and J. Y. Harrington, 2000: Dynamics and energetics of the cloudy boundary layer in simulations of off-ice flow in the marginal ice zone. J. Geophys. Res., 105, 11 889-11900.

Paluch, I. R., and D. H. Lenschow, 1991: Stratiform cloud formation in the marine boundary layer. J. Atmos. Sci., 48, 21412158.

Pinto, J. O., 1998: Autumnal mixed-phase cloudy boundary layers in the Arctic. J. Atmos. Sci., 55, 2016-2038.

- , and J. A. Curry, 1995: Atmospheric convective plumes emanating from leads. 2. Microphysical and radiative processes. $J$. Geophys. Res., 100, 4633-4642.

Pruppacher, H. R., and J. D. Klett, 1978: Microphysics of Clouds and Precipitation. D. Reidel, $714 \mathrm{pp}$.

Rauber, R. M., and A. Tokay, 1991: An explanation for the existence of supercooled water at the top of cold clouds. $J$. Atmos. Sci., 48, 1005-1023.

Sassen, K., 1984: Deep orographic cloud structure and composition derived from comprehensive remote sensing measurements. J. Climate Appl. Meteor., 23, 568-583.

Shupe, M. D., 2007: A ground-based multiple remote-sensor cloud phase classifier. Geophys. Res. Lett., 34, L22809, doi:10.1029/2007GL031008.

—_, and J. M. Intrieri, 2004: Cloud radiative forcing of the Arctic surface: The influence of cloud properties, surface albedo, and solar zenith angle. J. Climate, 17, 616-628.

_ , P. Kollias, S. Y. Matrosov, and T. L. Schneider, 2004: Deriving mixed-phase cloud properties from Doppler radar spectra. J. Atmos. Oceanic Technol., 21, 660-670.
_ ics retrievals from surface-based remote sensors at SHEBA. J. Appl. Meteor., 44, 1544-1562.

—, S. Y. Matrosov, and T. Uttal, 2006: Arctic mixed-phase cloud properties derived from surface-based sensors at SHEBA. J. Atmos. Sci., 63, 697-711.

— P. Kollias, M. Poellot, and E. Eloranta, 2008: On deriving vertical air motions from cloud radar Doppler spectra. $J$. Atmos. Oceanic Technol., 25, 547-557.

Sun, Z., and K. P. Shine, 1994: Studies of the radiative properties of ice and mixed-phase clouds. Quart. J. Roy. Meteor. Soc., 120, 111-137.

Tiedtke, M., 1993: Representation of clouds in large-scale models. Mon. Wea. Rev., 121, 3040-3061.

Tremblay, A., A. Glazer, W. Yu, and R. Benoit, 1996: A mixedphase cloud scheme based on a single prognostic equation. Tellus, 48A, 483-500.

Turner, D. D., S. A. Clough, J. C. Liljegren, E. E. Clothiaux, K. Cady-Pereira, and K. L. Gaustad, 2007: Retrieving liquid water path and precipitable water vapor from the Atmospheric Radiation Measurement (ARM) microwave radiometers. IEEE Trans. Geosci. Remote Sens., 45, 3689-3690.

Vali, G., R. D. Kelly, J. French, S. Haimov, D. Leon, R. E. McIntosh, and A. Pazmany, 1998: Finescale structure and microphysics of coastal stratus. J. Atmos. Sci., 55, 3540-3564.

Verlinde, H., and Coauthors, 2007: The Mixed-Phase Arctic Cloud Experiment. Bull. Amer. Meteor. Soc., 88, 205-221.

Westwater, E. R., Y. Han, M. D. Shupe, and S. Y. Matrosov, 2001: Analysis of integrated cloud liquid and precipitable water vapor retrievals from microwave radiometers during the Surface Heat Budget of the Arctic Ocean project. J. Geophys. Res., 106, 32 019-32 030.

Zhang, J., and U. Lohmann, 2003: Sensitivity of single column model simulations of Arctic springtime clouds to different cloud cover and mixed phase cloud parameterizations. $J$. Geophys. Res., 108, 4439, doi:10.1029/2002JD003136.

Zuidema, P., and Coauthors, 2005: An Arctic springtime mixedphase cloudy boundary layer observed during SHEBA. $J$. Atmos. Sci., 62, 160-176. 